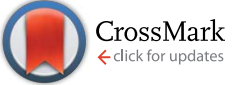

Cite this: J. Mater. Chem. A, 2015, 3, 15357

Received 19th March 2015 Accepted 27th April 2015

DOI: $10.1039 / c 5 t a 02040 a$

www.rsc.org/MaterialsA

\section{New aspects in bis and tris(dipyrrinato)metal complexes: bright luminescence, self-assembled nanoarchitectures, and materials applications}

\author{
Ryota Sakamoto, ${ }^{*}$ Toshiki Iwashima, Mizuho Tsuchiya, Ryojun Toyoda, \\ Ryota Matsuoka, Julius F. Kögel, Shinpei Kusaka, Ken Hoshiko, Toshiki Yagi, \\ Tatsuhiro Nagayama and Hiroshi Nishihara*
}

Dipyrrins serve as monovalent bidentate ligand molecules that coordinate to various cations. Their $\mathrm{BF}_{2}$ complexes, 4,4-difluoro-4-bora-3a,4a-diaza-s-indacene and its derivatives (BODIPYs), exhibit excellent photostability, strong light absorption, and high fluorescence quantum yield, thereby encouraging their application in various fields, e.g., as biological and biomedical fluorescent markers. Dipyrrin may also accept a wide variety of metal ions spontaneously. However, dipyrrin metal complexes have been disregarded from materials science research. This review article summarizes recent progress in bis(dipyrrinato)metal(॥) and tris(dipyrrinato)metal(III) complexes from the viewpoint of materials chemistry. Section 2 describes a series of efforts aimed to realize intense luminescence superior to or comparable with that of BODIPYs. The spontaneous coordination of these complexes enables them to construct self-assembled nanoarchitectures, such as supramolecules and coordination polymers that form one-dimensional nanowires, two-dimensional nanosheets, and metal-organic frameworks. Section 3 describes such alluring molecular superstructures. Section 4 discusses potential applications based on these nanoarchitectures, such as thermoelectric and photoelectric conversion.

\section{Introduction}

Dipyrrin comprises two pyrroles bridged by a methine bridge, where the two rings are inequivalent to pyrrolitic and iminic

Department of Chemistry, Graduate School of Science, The University of Tokyo, 7-3-1, Hongo, Bunkyo-ku, Tokyo 113-0033, Japan. E-mail: sakamoto@chem.s.u-tokyo.ac.jp; nisihara@chem.s.u-tokyo.ac.jp

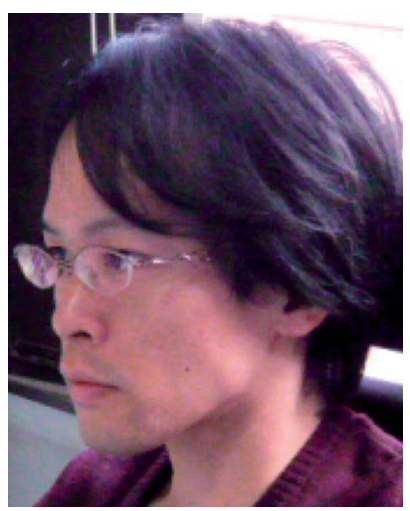

Ryota Sakamoto was born in Yamagata Village, Nagano, Japan in 1980. He graduated from The University of Tokyo (Japan) in 2002, and received his $P h D$ degree from the same university in 2007 under the supervision of Prof. Hiroshi Nishihara. Then he was appointed as an assistant professor at Tokyo University of Science (Japan), working with Prof. Takeshi Yamamura. In 2010 he moved to The University of Tokyo, joining Prof. Nishihara's group again. His current research interest lies in the construction of molecule-based nanostructures, and photonic and electronic devices using thereof. nitrogens (Fig. 1a). Upon deprotonation from the pyrrolitic nitrogen, dipyrrin undergoes resonance stabilization, such that the two rings are equivalent to each other (Fig. 1b). In this scheme, dipyrrin serves as a monovalent bidentate ligand molecule that coordinates to various cations to form complexes. ${ }^{\mathbf{1 - 1 5}}$ Among these complexes, the $\mathrm{BF}_{2}$ complexes of dipyrrin, 4,4-difluoro-4-bora-3a,4a-diaza-s-indacene (BODIPY,

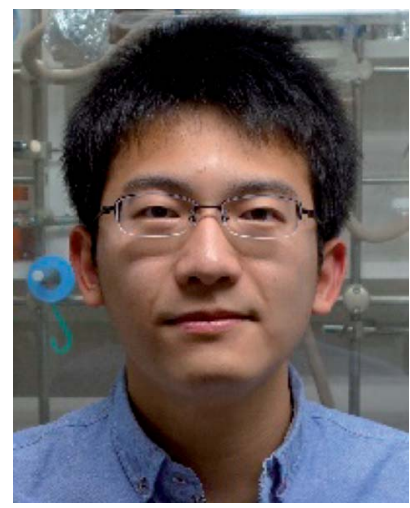

Toshiki Iwashima was born in Inazawa City, Aichi, Japan in 1993. He graduated from The University of Tokyo (Japan) in 2015. He is now pursuing his MSc degree with Prof. Hiroshi Nishihara in the Department of Chemistry at The University of Tokyo. His research interest lies in the synthetic design of organometallic complexes, and photonic and electronic devices using them. He is also fascinated by football and a big fan of Arsenal Football Club. 
(a)

(b)

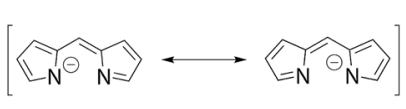

(c)<smiles></smiles>

(d)
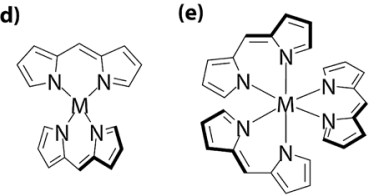

Fig. 1 Dipyrrin family: (a) dipyrrin; (b) dipyrrinate; (c) BODIPY; (d) bis(dipyrrinato)metal(॥) complex; (e) tris(dipyrrinato)metal(II) complex.

Fig. 1c) and its derivatives are the most famous and wellinvestigated ones because of their excellent photostability, strong light absorption in the visible and near infrared regions, and high fluorescence quantum yield $\left(\phi_{\mathrm{F}}\right) \cdot{ }^{5-16}$ In fact, BODIPYs are already on the market as biological and biomedical fluorescent markers and are being applied in devices such as solar cells and chemical sensors. However, dipyrrin can also accept a wide variety of metal ions, including nickel(II), copper(II), zinc(II), iron(III), cobalt(III), and rhodium(III), to form bis(dipyrrinato)metal(II) and tris(dipyrrinato)metal(III) complexes (Fig. 1d and e). ${ }^{1-4}$ Since the discovery of bis(dipyrrinato)metal complexes in $1924,{ }^{17}$ dipyrrin metal complexes have long been regarded as trivial substances in materials science.

This review article summarizes recent progress in the development of bis(dipyrrinato)metal(II) and tris(dipyrrinato) metal(III) complexes from the viewpoint of materials chemistry. Section 2 describes a series of efforts aimed to realize intense luminescence superior to or comparable with that of BODIPYs. Section 3 discusses the self-assembly of bis and tris(dipyrrinato) metal complexes, which results in the formation of alluring nanoarchitectures, such as supramolecules and coordination polymers giving rise to one-dimensional nanowires, twodimensional nanosheets, and metal-organic frameworks (MOFs) and porous coordination polymers (PCPs). Section 4 describes potential applications based on these nanoarchitectures.

\section{Pursuit of bright luminescence}

A plain BODIPY shows intense absorption and bright fluorescence at approximately $500 \mathrm{~nm}$, which are derived from the ${ }^{1} \pi-\pi^{*}$ transition of the dipyrrinato ligand..$^{5-16}$ The absorption and fluorescence may be redshifted upon the introduction of substituents on the dipyrrinato ligand, covering the 500-900 $\mathrm{nm}$ region. BODIPYs are good fluorophores even in polar solvents such as water. In sharp contrast, dipyrrin metal complexes have long been believed to be non-luminescent or weakly luminescent. This drawback seriously reduces the value of dipyrrinato-metal complexes in applications in which they serve, for example, as photosensitizers. In this section, the authors concentrate on efforts to improve the luminescent ability of bis and tris(dipyrrinato)metal complexes. For comprehensive knowledge on the whole types of luminescent dipyrrinato-metal complexes (i.e. mono(dipyrrinato)metal complexes with ancillary ligands other than dipyrrins), please see a comprehensive review article contributed by Baudron. ${ }^{2}$

\subsection{Introduction of bulky aryl groups at the meso-position}

The first essential improvement made to the fluorescence of dipyrrin-metal complexes was addressed by Lindsey, Bocian, and Holten, who focused on the steric effect of the peripheral

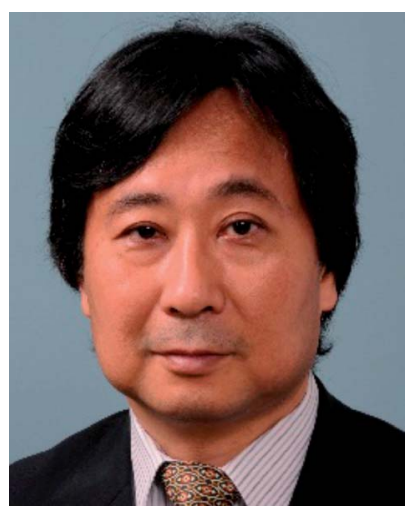

Hiroshi Nishihara received his BSc degree in 1977, MSc in 1979 and DSc in 1982 from The University of Tokyo. He was appointed research associate of the Department of Chemistry at Keio University in 1982, and he was promoted as lecturer in 1990, and associate professor in 1992. Since 1996, he has been a professor of the Department of Chemistry, School of Science at The University of Tokyo. He also worked as a visiting research associate of the Department of Chemistry at The University of North Carolina at Chapel Hill (1987-1989), and as a researcher of PRESTO, JST (1992-1996). He received The Chemical Society of Japan Award for Creative Work in 2003, Docteur Honoris Causa from the University of Bordeaux in 2011, and Commendation for Science and Technology by the MEXT in 2014. 
aryl group. ${ }^{18}$ The researchers demonstrated that the replacement of the phenyl group of bis(dipyrrinato)zinc(II) complex 1 with a 2,6-dimethylphenyl group (i.e., 2) transformed the molecule from a very weak emitter into highly fluorescent chromophore (Fig. 2). In toluene at room temperature, 1 and 2 exhibit absorption and fluorescence spectra similar to each other (Fig. 3). The spectral features of the compounds are associated with the ${ }^{1} \pi-\pi^{*}$ transition of the dipyrrinato ligand, similar to those of BODIPYs. Still, a subtle difference may be found with respect to the compounds' absorption and emission bandwidths, and Stokes shift is slightly reduced in 2 . This series of changes reflects lower conformational freedom in 2 , which is induced by the steric constraint between the 2,6-dimethylphenyl group and dipyrrinato ligand. This steric effect is clearly manifested in the fluorescence quantum yield $\left(\phi_{\mathrm{F}}=0.006\right.$ for 1 , 0.36 for 2 ) and fluorescence lifetime ( $\tau=90 \pm 10$ ps for $1,3 \pm 1$ ns for 2) (Table 1). However, the incorporation of a $t$-butyl group into 1 (i.e., complex 3), which has no associated steric interference, produces a $\phi_{\mathrm{F}}$ of 0.007 ; therefore, no enhancement in $\phi_{\mathrm{F}}$ is observed. This series of experimental findings suggests that hindering the internal rotation of the aryl group at the meso-position has a distinctive effect on the fluorescence quantum yield. Similar behavior has been reported for complexes 4 and 5, which have peripheral 1- and 2-naphthyl groups at the meso-position, respectively (Fig. 2 and Table 1). ${ }^{19}$ Possessing a greater steric constraint, 4 has shown photoluminescence intensities that are approximately three and ten times greater than those of $\mathbf{5}$ in THF and polymer media, respectively.

\subsection{Heteroleptic bis and tris(dipyrrinato)metal complexes}

Although introducing bulky aryl groups at the meso-position leads to fluorescence enhancement, quenching in polar solvents remains a serious problem. Sakamoto and Nishihara proposed that thermal transition/equilibrium from/between the emissive ${ }^{1} \pi-\pi *$ excited state $\left(\mathbf{D}^{*}-\mathbf{Z n}-\mathbf{D}\right.$ or $\left.\mathbf{D}-\mathbf{Z n}-\mathbf{D}^{*}\right)$ to/and non-emissive

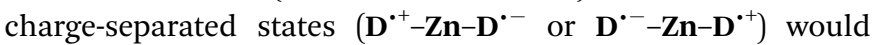
suppress the fluorescence of a bis(dipyrrinato)zinc(II) complex, where $\mathbf{D}$ and $\mathbf{Z n}$ denote a dipyrrinato ligand and $\mathrm{Zn}^{2+}$ ion, respectively (Fig. 4a). ${ }^{\mathbf{2 0 1} 21}$ The complex may be regarded as a

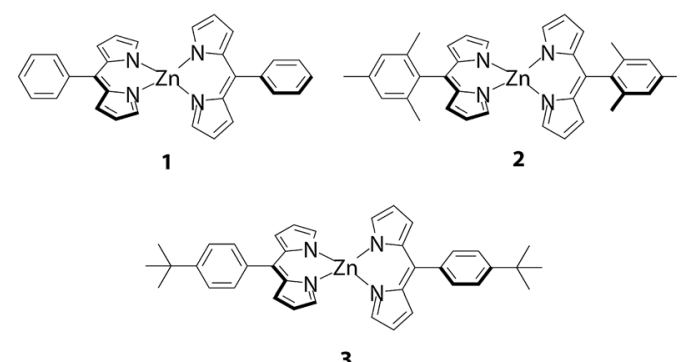

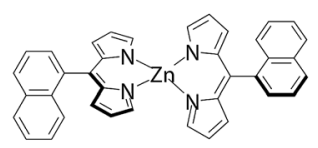

4

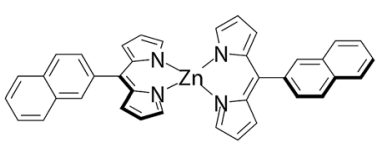

5
Fig. 2 Luminescent bis(dipyrrinato)zinc(I) complexes 1-5

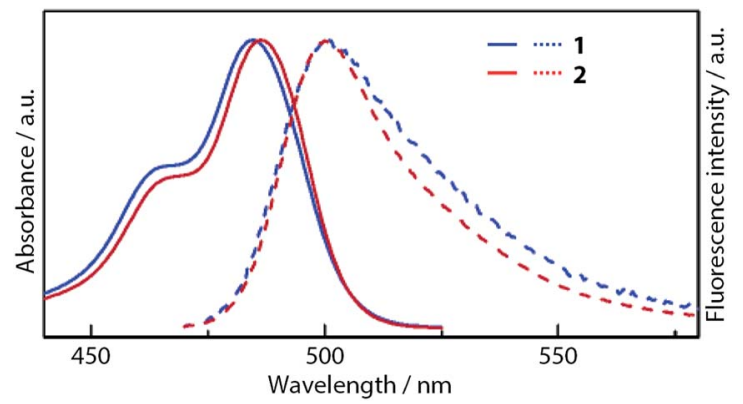

Fig. 3 Absorption and fluorescence spectra of 1 and 2. Adapted with permission from ref. 18. Copyright 2004 American Chemical Society.

bichromophoric molecule, in which two dye entities (dipyrrinato ligands) are ligated by a zinc(II) ion. Photoexcitation in bichromophoric systems often results in the formation of charge-separated states, which are generated by one-electron transfer. ${ }^{2-24} 9,9^{\prime}$-Bianthryl is a representative example of such a system..$^{22,23}$ The charge-separated state is known to be stabilized in polar solvents.

To verify the present hypothesis, and to improve $\phi_{\mathrm{F}}$, Sakamoto and Nishihara synthesized a series of zinc(II) complexes 6-8 (Fig. 5). ${ }^{20}$ A small number of heteroleptic bis(dipyrrinato) metal complexes have been reported by Cohen, ${ }^{25}$ and Radecka, ${ }^{26,27}$ and Dolphin, ${ }^{28}$ however, $\mathbf{8}$ is still the first example of a heteroleptic zinc(II) complex that contains two types of dipyrrinato ligands with drastic differences in their electronic structures: one derived from either of the homoleptic complexes 6 and 7. Fig. 6 shows the absorption and fluorescence spectra of 6-8, and their numerical data are collected in Table 1 . Complex 7, with (4-methyphenyl)ethynyl substituents at the $\beta$-position, shows bathochromic shifts in its absorption and fluorescence maxima because of $\pi$-extension. Heteroleptic complex 8 features two absorption bands, corresponding to those of 6 and 7 with no obvious shift in wavelength, thereby suggesting no distinctive orbital interaction between the two dipyrrinato ligands both in the ground and excited states. However, 8 exhibits remarkable emission behavior; it exhibits very high $\phi_{\mathrm{F}}$ in toluene $\left(\phi_{\mathrm{F}}=0.76\right)$, and the bright fluorescence is sustained even in polar dichloromethane $\left(\phi_{\mathrm{F}}=0.52\right)$. This series of luminescence behaviors contrasts with the behaviors observed for 6 and 7, which undergo significant quenching from non-polar toluene to polar dichloromethane $\left(\phi_{\mathrm{F}}=0.28 \rightarrow\right.$ 0.00 for $6, \phi_{\mathrm{F}}=0.72 \rightarrow 0.27$ for 7 ). DFT calculation indicates that the configuration of the frontier orbitals ( $\pi$ and $\pi^{*}$ orbitals of each dipyrrinato ligand) in heteroleptic complex 8 thwarts thermal transition from the emissive ${ }^{1} \pi-\pi^{*}$ state to the nonfluorescent charge-separated states, thereby leading to a greater $\phi_{\mathrm{F}}$ (Fig. 4b). This positive effect is highlighted in polar solvents. It is also noteworthy for heteroleptic complex 8 that excitation at each ligand results in exclusive emission from the $\pi$-extended ligand at the same $\phi_{\mathrm{F}}$ (Fig. 6 and Table 1). This result demonstrates the presence of quantitative energy transfer between the two dipyrrinato ligands.

Following the publication of the report by Sakamoto and Nishihara, experimental proof was provided by Thompson and 
Table 1 Photochemical properties of complexes 1-13 at room temperature in fluid solutions

\begin{tabular}{|c|c|c|c|c|c|c|c|c|}
\hline Compound & Central metal & Solvent & $\lambda_{\mathrm{abs}}{ }^{a}(\mathrm{~nm})$ & $\lambda_{\text {ex }}(\mathrm{nm})$ & $\lambda_{\mathrm{em}}(\mathrm{nm})$ & $\phi_{\mathrm{F}}$ & $\tau(\mathrm{ns})$ & Ref. \\
\hline 1 & $\mathrm{Zn}(\mathrm{II})$ & Toluene & 485 & 480 & 501 & 0.006 & $0.09 \pm 0.01$ & 18 \\
\hline 2 & $\mathrm{Zn}(\mathrm{II})$ & Toluene & 487 & 480 & 500 & 0.36 & $3 \pm 1$ & 18 \\
\hline 4 & $\mathrm{Zn}(\mathrm{II})$ & THF & 485 & - & 516 & - & - & 19 \\
\hline 5 & $\mathrm{Zn}(\mathrm{II})$ & THF & 486 & - & 518 & - & - & 19 \\
\hline 6 & $\mathrm{Zn}(\mathrm{II})$ & Toluene & 495 & 495 & 509 & $0.28\left(0.00^{b}\right)$ & - & 20 \\
\hline & & & & 553 & 578 & $0.75\left(0.49^{b}\right)$ & - & 20 \\
\hline 9 & In(III) & Hexanes & 444,496 & 448 & 522 & 0.074 & $1.93 \pm 0.02$ & 25 \\
\hline 10 & $\operatorname{In}(\mathrm{III})$ & Toluene & 459,570 & 459 & 592 & $0.41\left(0.053^{b}\right)$ & 2.44 & 26 \\
\hline 11 & In(III) & Toluene & 478,564 & 480 & 596 & $0.34\left(0.021^{b}\right)$ & 2.53 & 26 \\
\hline 12 & $\mathrm{In}(\mathrm{III})$ & Toluene & 528,572 & 530 & 600 & $0.28\left(0.015^{b}\right)$ & 2.49 & 26 \\
\hline 13 & $\mathrm{Zn}(\mathrm{II})$ & Toluene & 485,646 & 490,600 & 672 & 0.00043 & - & 30 \\
\hline
\end{tabular}

${ }^{a}{ }^{1} \pi-\pi^{*}$ bands are shown. ${ }^{b}$ In dichloromethane.

(a) Homoleptic complexes 6 and 7

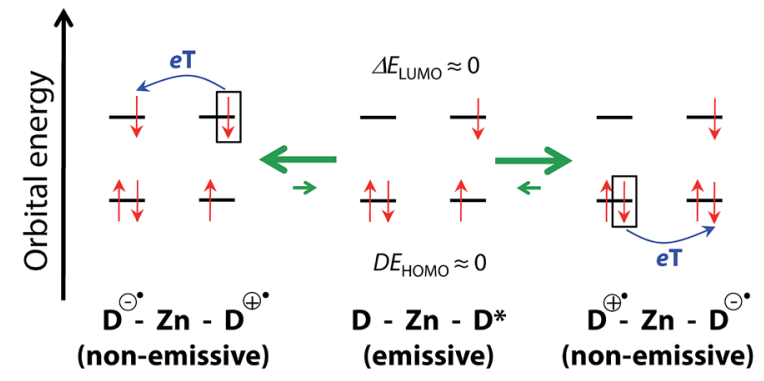

(b) Heteroleptic complex 8

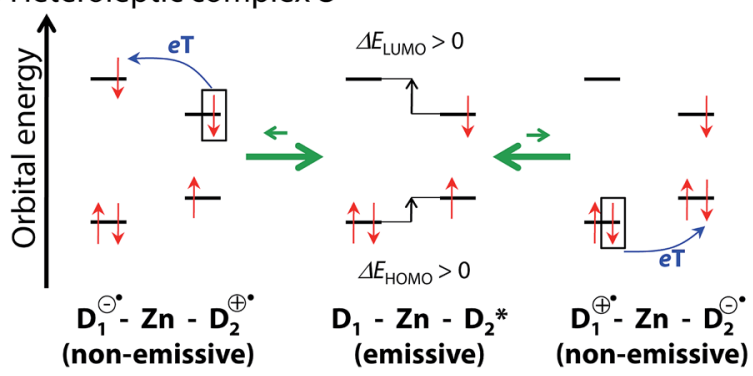

Fig. 4 Schematic illustrations for plausible thermal equilibria among the two non-emissive charge-separated states $\left(D^{++}-Z n-D^{--}\right.$and

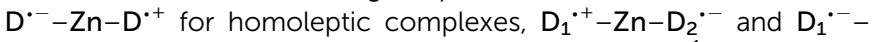
$\mathrm{Zn}-\mathrm{D}_{2}{ }^{\cdot+}$ for heteroleptic complexes) and the emissive ${ }^{1} \pi-\pi^{*}$ excited state localized on the right-hand dipyrrinato ligand $(D-Z n-D *$ for homoleptic complexes, $D_{1}-Z n-D_{2}^{*}$ for heteroleptic complexes) in a polar solvent. $\mathrm{eT}$ indicates an electron transfer process. $\mathrm{Zn}$ and $\mathrm{D}$ represent the $\mathrm{Zn}^{2+}$ center and dipyrrinato ligand, respectively. Adapted with permission from ref. 20. Copyright 2012 John Wiley \& Sons, Inc.

coworkers that indicated that the charge-separated state is the chief non-radiative pathway in homoleptic bis(dipyrrinato)zinc(II) complexes. ${ }^{29}$ The authors performed transient absorption spectroscopy, thereby disclosing that ${ }^{1} \pi-\pi^{*}$ photoexcited homoleptic complexes undergo symmetry-breaking charge transfer to produce the charge-separated state in polar solvents. They also elucidated that in non-polar solvents such as toluene,
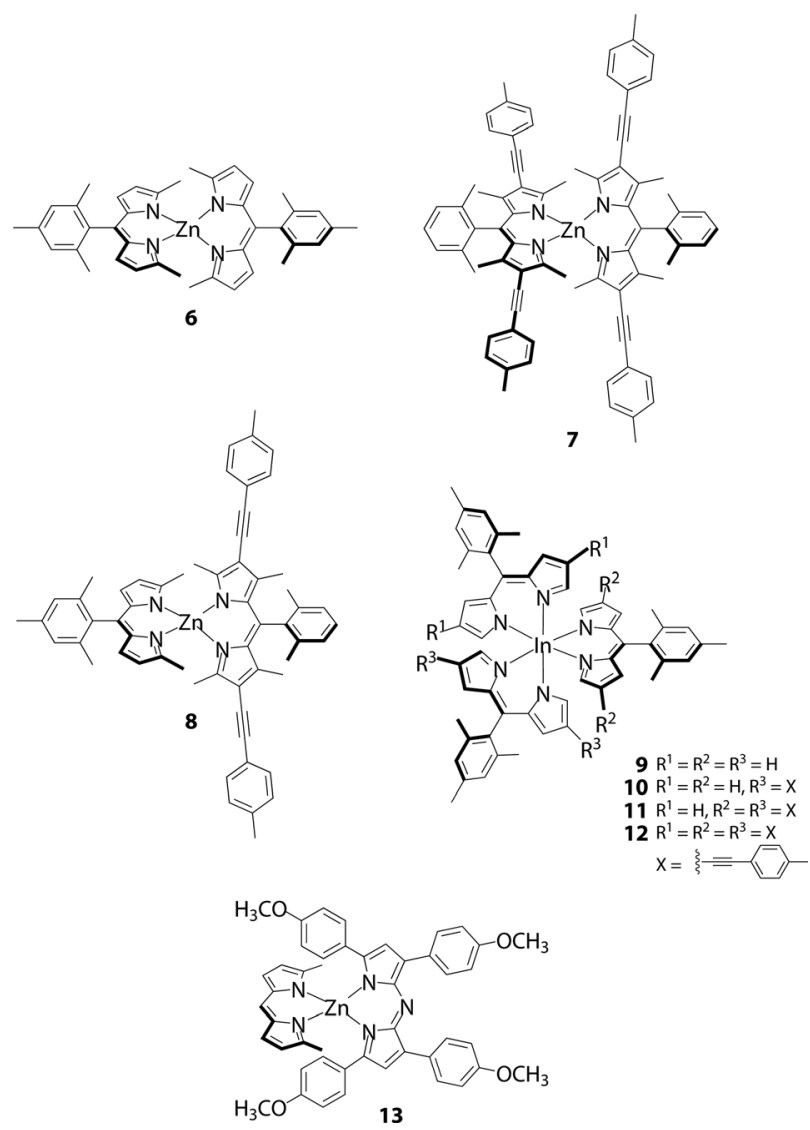

Fig. 5 Luminescent heteroleptic bis(dipyrrinato)zinc(॥) complex 8, tris(dipyrrinato)indium(II) complexes 10 and 11, and dipyrrinato-azadipyrrinato hybrid complex 13 . Corresponding homoleptic complexes 6, 7, 9 and 12 are also shown.

thermal equilibrium occurs between the ${ }^{1} \pi-\pi *$ state and the charge-separated state.

To demonstrate the generality and utility of their strategy, Sakamoto and Nishihara pursued extensions to other dipyrrinato-metal complex systems. Cohen and co-workers reported 


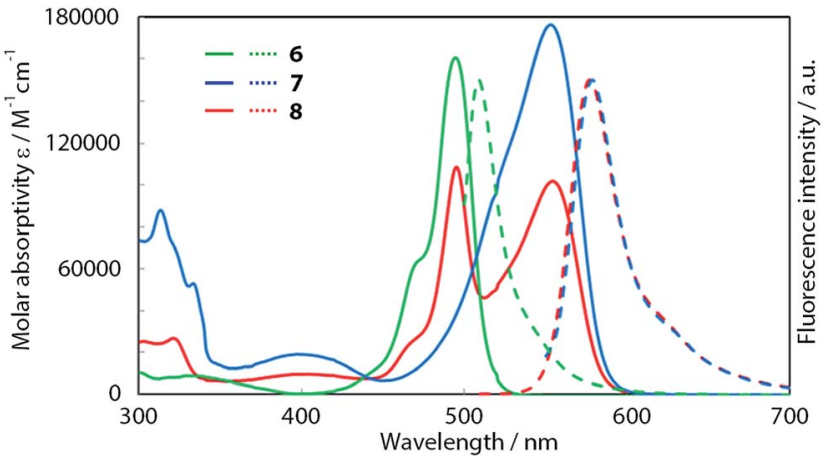

Fig. 6 Absorption (solid lines) and fluorescence spectra (dotted lines) of 6 (green), 7 (blue), and 8 (red) in toluene. Adapted with permission from ref. 20. Copyright 2012 John Wiley \& Sons, Inc.

that homoleptic tris(dipyrrinato)gallium(III) and indium(III) complexes were weak emitters; ${ }^{30}$ however, heteroleptic indiu$\mathrm{m}$ (III) complexes 10 and 11 (Fig. 5) exhibit higher $\phi_{\mathrm{F}}(0.41$ and 0.34 in toluene, respectively) than the corresponding homoleptic complexes 9 and $\mathbf{1 2}\left(\phi_{\mathrm{F}}=0.074\right.$ and 0.28 in hexanes and toluene, respectively) (Table 1). ${ }^{31}$ Surprisingly, the $\phi_{\mathrm{F}}$ of 9 is greater than that of the corresponding $\pi$-expanded BODIPY $\left(\phi_{\mathrm{F}}=0.35\right)$. This finding is of great interest because it counters the preconception that BODIPYs emit more brightly than dipyrrinato-metal complexes.

Bis(azadipyrrinato)zinc(II) complexes were believed to be non-fluorescent, ${ }^{32-34}$ in contrast to the behavior observed for $\mathrm{BF}_{2}$ complexes of azadipyrrins (azaBODIPY). However, Sakamoto and Nishihara revealed that dipyrrinato-azadipyrrinato hybrid zinc(II) complex 13 exhibited detectable fluorescence (Fig. 5 and Table 1)..$^{35}$

\subsection{Other molecules}

Telfer and coworkers reported that homoleptic tris(dipyrrinato)rhodium(III) complexes emitted weakly. ${ }^{36}$ Several supramolecular and coordination polymeric systems show luminescence, as will be discussed in Section 3. Mono(dipyrrinato)metal complexes containing $\mathrm{Sn}(\mathrm{I}),{ }^{37} \mathrm{Cu}(\mathrm{I}),{ }^{38,39} \operatorname{Re}(\mathrm{I}){ }^{40} \mathrm{Pt}(\mathrm{II}),{ }^{41} \mathrm{Pd}(\mathrm{II}),{ }^{41}$ $\operatorname{Ir}(\mathrm{III}),{ }^{42-44} \mathrm{Rh}(\mathrm{III}),{ }^{45} \mathrm{Sn}(\mathrm{IV}),{ }^{46} \mathrm{Al}(\mathrm{III}),{ }^{47} \mathrm{Si}(\mathrm{IV}),{ }^{48} \mathrm{Ca}(\mathrm{II}),{ }^{49} \mathrm{Zn}$ (II), ${ }^{49}$ and $\mathrm{Mg}(\mathrm{II})^{50,51}$ centers also exhibited luminescence, the details of which are discussed in a comprehensive review. ${ }^{2}$

\section{Creation of self-assembled nanoarchitectures}

A distinctive advantage of (dipyrrinato)metal complexes over BODIPYs is that they may construct supramolecular and polymer assemblies by taking advantage of facile and spontaneous coordination reactions and multiple coordination sites on the metal centers. In the following section, supramolecules, onedimensional and two-dimensional coordination polymeric systems, and MOFs and PCPs based on (dipyrrinato)metal complexes are introduced.

\subsection{Supramolecules}

The development of bis and tris(dipyrrinato)metal complexes is not confined to simple mononuclear ones as described in the previous section. Because many metal ions may accept two or more dipyrrin ligands, supramolecular assemblies linked by bis and tris(dipyrrinato)metal complexes may be designed and obtained. Indeed, the appropriate design of dipyrrin ligands affords supramolecules with intriguing structures.

Numerous multinuclear bis and tris(dipyrrinato)metal complexes featuring oligo(dipyrrin)s, or ligands with multiple dipyrrin subunits joined by spacers, have been developed to date..$^{52-72}$ The length, position, and flexibility of these spacers affect the geometry of resultant metal complexes; their geometries include double-stranded helical, ${ }^{52-61,65-72}$ triple-stranded helical, ${ }^{62}$ triangular, ${ }^{61,64}$ rhombic, ${ }^{63,64}$ and hexagonal. ${ }^{63}$

Especially, a number of reports have described the formation of double-stranded helices. These complexes can be obtained by bis(dipyrrin) ligands with spacers exhibiting modest flexibility, such as short alkyl chains, ${ }^{52-55,57,60}$ sulfur, ${ }^{56}$ and 4-alkoxyphenylene spacers. ${ }^{58,59}$ Focusing on the chirality of doublestranded complexes, the Thompson group prepared enantiomeric bis(dipyrrin)s 14a,b to conduct diastereoselective complexation reactions to obtain double-stranded helical bis(dipyrrinato)zinc(II) complexes 15a,b (Fig. 7). ${ }^{57}$ Circular Dichroism (CD) spectroscopy, NMR spectroscopy, and chiral HPLC analysis revealed that ligands 14a,b underwent complexation with nearly a $1: 1$ mixture of diastereomeric helicates, and 15a,b did not show stereochemical inversion in solution.

Maeda and co-workers developed meso-aryl dipyrrin dimers whose dipyrrin moieties are linked together at the 2 and $2^{\prime}$ positions to construct double-stranded helicates with zinc(II) ions (Fig. 8)..$^{58}$ Although complexes without straps to interlock the aryl group 16a-d are known to undergo racemization in solution, those with straps, e.g., 17a,b, retain their chirality. Variable-temperature CD spectroscopy and fluorescence lifetime measurements have revealed that the interlocked species exhibit a temperature-dependent spring-like motion, where the distance between the zinc centers fluctuates. The same group has developed a class of similar complexes and demonstrated that there are two conformations in the complexes, S (short, contracted) and L (long, stretched) (Fig. 9)..$^{59}$ Although the latter is favored theoretically, X-ray crystallography and variable temperature absorption spectroscopy revealed that the two modes are interchangeable in $\mathbf{1 8 .}$

Although double-stranded complexes are not reported to be intensely emissive in general, ${ }^{56,58,59}$ Antina, V'yugin, and coworkers reported that several complexes exhibited bright emission. ${ }^{4,65-71}$ For example, zinc(II) complex 19 tethered with a methylene linker at the 3 and $3^{\prime}$ positions fluoresces at $543 \mathrm{~nm}$ with a $\phi_{\mathrm{F}}$ of 0.91 in cyclohexane (Fig. 10) ${ }^{66}$ It is notable that even heavier $\mathrm{d}^{10}$ metal complexes show fluorescence; a $\mathrm{Cd}(\mathrm{II})$ analogue emits at $537 \mathrm{~nm}$ with a $\phi_{\mathrm{F}}$ of 0.27 in cyclohexane, ${ }^{69}$ whereas a $\mathrm{Hg}$ (II) counterpart luminesces at $538 \mathrm{~nm}$ with a $\phi_{\mathrm{F}}$ of $0.034 .{ }^{68}$ 


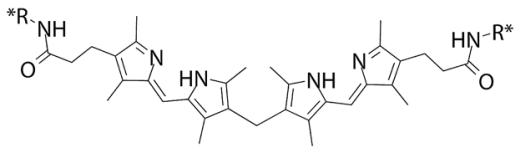

$14 a, b$

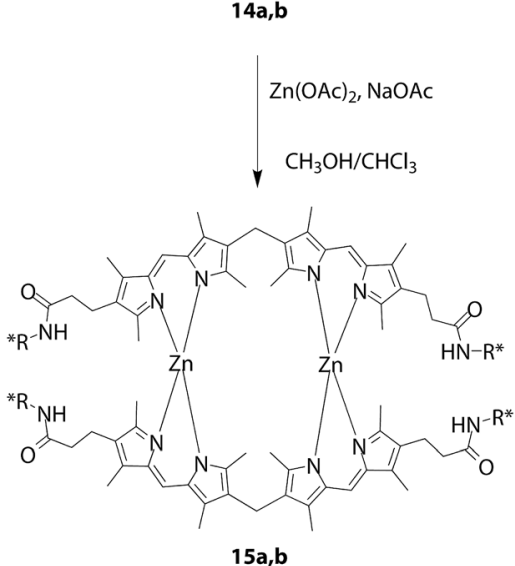

$\mathrm{R}^{*}=\stackrel{*}{\mathrm{Ph}}$

Fig. 7 Double-stranded helical zinc(॥) complexes 15a,b comprising bis(dipyrrin)s 14a,b with an accessory chiral amide.

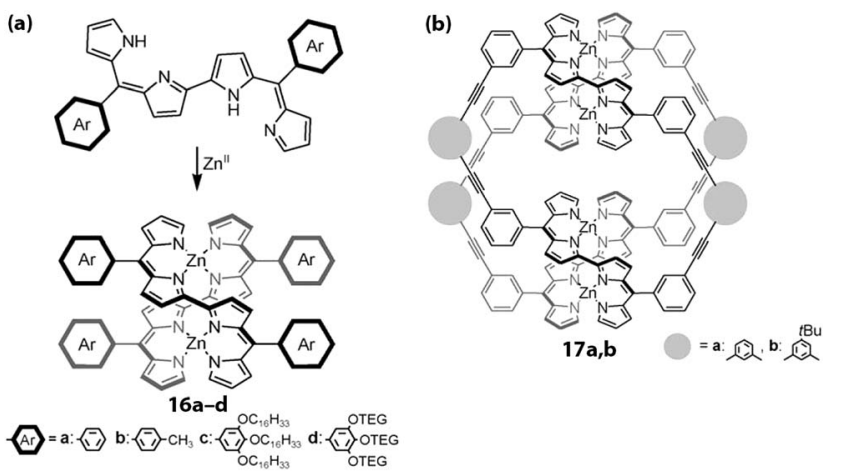

Fig. 8 Double-stranded helical complexes. (a) Double helical complexes $16 \mathrm{a}-\mathrm{d}$ without straps on the meso-aryl group. OTEG $=\mathrm{a}$ triethyleneglycol chain. (b) Double helical complexes 17a,b with linking straps on the meso-aryl group. Adapted with permission from ref. 58. Copyright 2010 Wiley-VCH Verlag GmbH \& Co. KGaA, Weinheim.

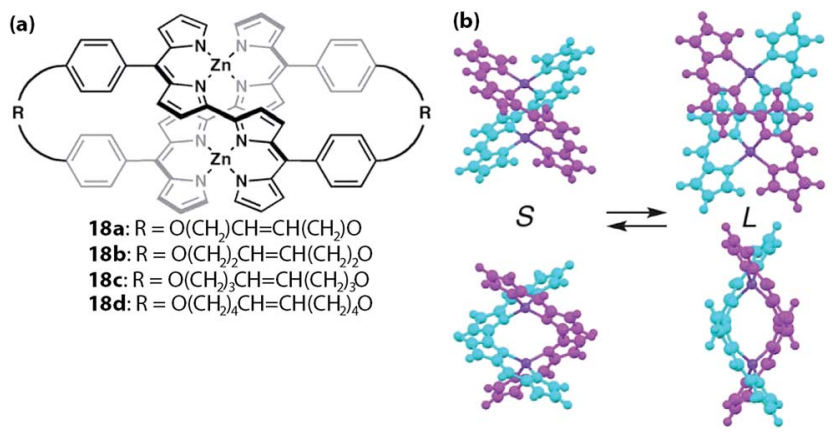

Fig. 9 (a) Double-stranded helical complex 18. (b) Two possible conformations. Adapted with permission from ref. 59. Copyright 2013 The Royal Society of Chemistry.
As previously mentioned, supramolecular assemblies with geometries other than double-stranded helicates have also been reported. Dolphin's group synthesized ring-fused bis(dipyrrin)s 20-22 to prepare rhombic (23-25) and hexagonal (26) multinuclear zinc(II) complexes (Fig. 11). ${ }^{63}$ The distance between the two adjacent zinc(II) centers is $8.2 \AA$ for both complexes, but the diagonal distances are $9.19 \AA$ and $13.80 \AA$ for the rhombic and hexagonal complexes, respectively. However, Maeda and coworkers reported dinuclear and trinuclear bis(dipyrrinato)zinc(II) and nickel(II) complexes (e.g., 27 and 28, Fig. 12) with dipyrrin dimers tethered at an acute angle (Fig. 12). ${ }^{64}$ The presence of $\alpha$-methyl groups alters the selectivity of the dinuclear and trinuclear configurations because of their steric repulsion around the metal center. The packing structure of $\mathbf{2 8}$ provided a smooth hole conduction pathway, up to a mobility of $0.11 \mathrm{~cm}^{2} \mathrm{~V}^{-1} \mathrm{~s}^{-1}$ (from a non-contact flash-photolysis timeresolved microwave conductivity measurement), along the aligned axis of the trinuclear assembly.

\subsection{One-dimensional coordination polymers}

Maeda and coworkers synthesized one-dimensional polymers 29 or 30 (Fig. 13a and b). ${ }^{73,74}$ By mixing the corresponding dipyrrin dimer and zinc(II) acetate in a molar ratio of $1: 1$ in THF, the desired one-dimensional coordination polymer featuring the bis(dipyrrinato)zinc(II) motif is generated spontaneously. The polymer strands are dispersible in the medium, showing uniform nanosized spherical structures with diameters measured to be approximately $0.3 \mu \mathrm{m}$ by scanning electron microscopy (SEM) images (Fig. 13c and d), and approximately $0.1 \mu \mathrm{m}$ by dynamic light scattering (DLS). The nanospheres contain the constitutive zinc element as shown in Fig. 13c. Additionally, the microspheres emit green fluorescence (Fig. 13d). The authors ascribed the formation of the nanospheres to three steps: (1) formation of the coordination oligomers; (2) stacking of the oligomers; and (3) conversion to spheres.

Dolphin employed a linear and rigid bridging dipyrrin dimer to create bis(dipyrrinato)cobalt(II) complex chains up to pentanuclear ones. ${ }^{28}$ Single strands of bis(dipyrrinato)zinc(II) coordination polymers were synthesized and isolated by Sakamoto and Nishihara (Fig. 14). ${ }^{75}$ This series of materials is easy to fabricate: by simply mixing two solutions, a dichloromethane solution of 31 or $\mathbf{3 2}$ and an ethanol solution of metal(II) acetate (metal $=\mathrm{Zn}, \mathrm{Ni}$, and $\mathrm{Cu}$ ), coordination polymers $33-\mathbf{3 6}$ are obtained (Fig. 14a and b). A distinctive feature of the molecular system is that it may be crystallized: a liquid/liquid interfacial

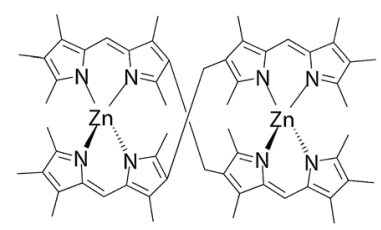

19

Fig. 10 Brightly luminescent double-stranded helical complex 19 

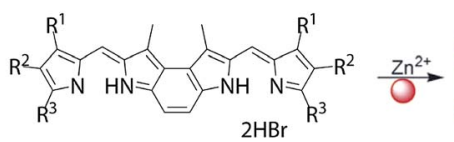

20: $R^{1}=R^{2}=R^{3}=H$
21: $R^{1}=C_{2} H_{5}, R^{2}=C_{3}, R^{3}=$
22: $R^{1}=C_{2} H_{5}, R^{2}=C_{3}, R^{3}=-\mathrm{OCH}_{3}$

Fig. 11 Rhombic (23-25) and hexagonal (26) multinuclear bis(dipyrrinato)zinc(॥) complexes using ring-fused bis(dipyrrin)s 20-22. Adapted with permission from ref. 63. Copyright 2011 The Royal Society of Chemistry.
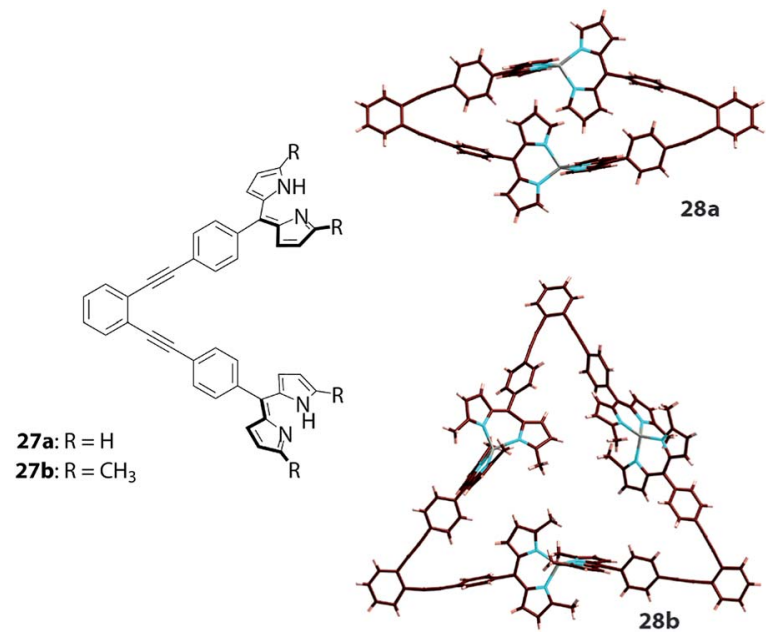

Fig. 12 Bis(dipyrrin)s 27a and 27b and corresponding multinuclear bis(dipyrrinato)zinc(॥) complexes with triangular and linear structures (28a and 28b). Adapted with permission from ref. 64. Copyright 2013 Wiley-VCH Verlag GmbH \& Co. KGaA, Weinheim.

reaction between ligand $\mathbf{3 1}$ and metal(II) acetate affords single crystals of 33-35 suitable for X-ray diffraction analysis (Fig. 14cf). In addition, the crystalline or solidified wires may be disentangled into single strands upon ultrasonication in organic solvents. A suspension of $\mathbf{3 3}$ showed Tyndall scattering (Fig. 14g), whereas luminescence dominated Tyndall scattering in a suspension of $\mathbf{3 6}$, with a quantum yield of $8 \%$ in toluene (Fig. 14h). The isolated fibers of $\mathbf{3 3}$ and $\mathbf{3 6}$ were imaged by atomic force microscopy (AFM), with the suspension sampled on flat HOPG substrates (Fig. 14i-1). Interestingly, the strands were observed as straight lines, the heights of which (0.7 and 1.9 $\mathrm{nm}$ ) were consistent with the corresponding mononuclear complexes (0.65 and $1.8 \mathrm{~nm})$.

Cohen and coworkers reported one-dimensional coordination polymers based on mono(dipyrrinato)copper(II) complexes with the acetylacetonato type of ancillary ligands. ${ }^{76-78}$ At the meso-position, additional coordination sites were implanted, such as pyridyl, 4-cyanophenyl, and 4-methylthiophenyl groups, which allowed the molecular system to adopt one-dimensional polymeric forms in the crystal phase.
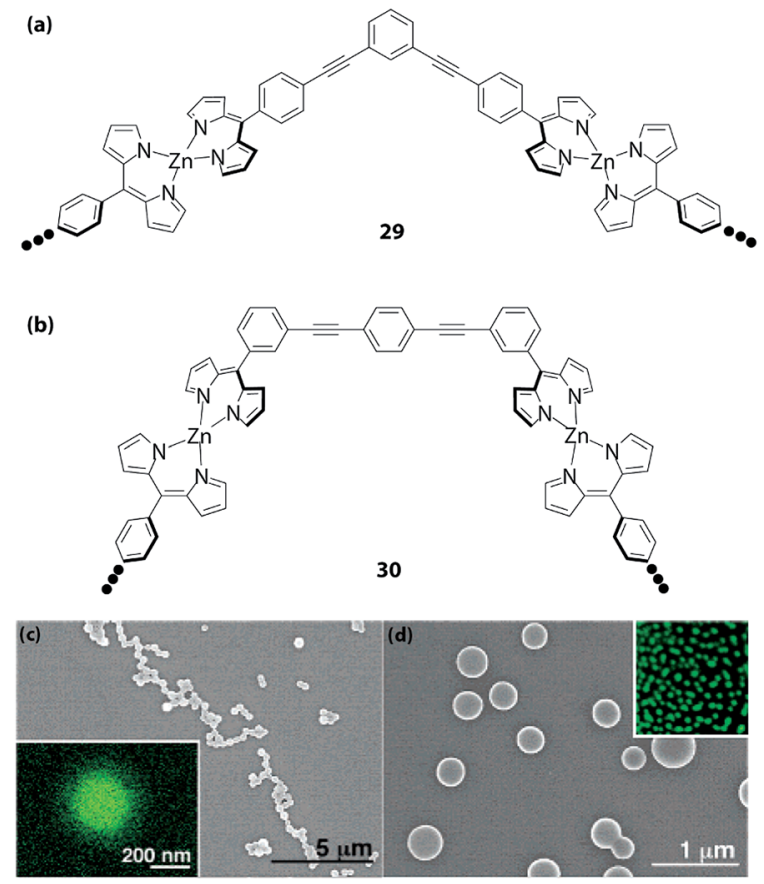

Fig. 13 One-dimensional bis(dipyrrinato)zinc(॥) complex polymers (a) 29 and (b) 30. (c) SEM image of one-dimensional coordination polymer 29. The inset shows Zn mapping drawn by HRTEM/EDX. (d) SEM image of one-dimensional coordination polymer 30 . The inset shows a fluorescence micrograph with a $25 \mu \mathrm{m}$ side of each square. Adapted with permission from ref. 73. Copyright 2006 American Chemical Society.

\subsection{Two-dimensional coordination polymer}

Sakamoto and Nishihara created the two-dimensional polymer 37 comprising the bis(dipyrrinato)zinc(II) complex motif (Fig. 15). ${ }^{79}$ Nanosheets 37 were composed of the three-way dipyrrin ligand $\mathbf{3 8}$ and zinc(II) ions and could be effectively synthesized by interfacial fabrication processes. Multi-layer 37 was synthesized by a liquid/liquid interfacial reaction, in which a dichloromethane solution of $\mathbf{3 8}$ was layered with an aqueous solution of zinc(II) acetate under ambient conditions (Fig. 15b and c). The spontaneous complexation between ligand 38 and zinc(II) ions then occurred at the liquid/liquid interface, such that the desired two-dimensional network structure was formed. The multi-layer nanosheets exhibited a sheet morphology both macroscopically and microscopically (Fig. 15d-g). The thickness of multi-layer 37 may be controlled by the concentration of 38, spanning from 6 to $800 \mathrm{~nm}$ (corresponding to 5-670 layers). The authors also indicated that a series of conventional single-phase syntheses resulted in solid materials with disordered structures. However, an air/liquid interfacial reaction gives rise to single-layer or few-layer 37 (Fig. 15h and i). In this process, a diluted dichloromethane solution of ligand $\mathbf{3 8}$ was gently sprayed under ambient conditions. After spontaneous evaporation of dichloromethane, spontaneous nanosheet formation occurred at the air/liquid interface. The nanosheet could be salvaged from the interface and deposited onto various flat substrates. Fig. $15 \mathrm{j}-\mathrm{n}$ show a 
(a)

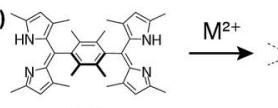

31

(b)

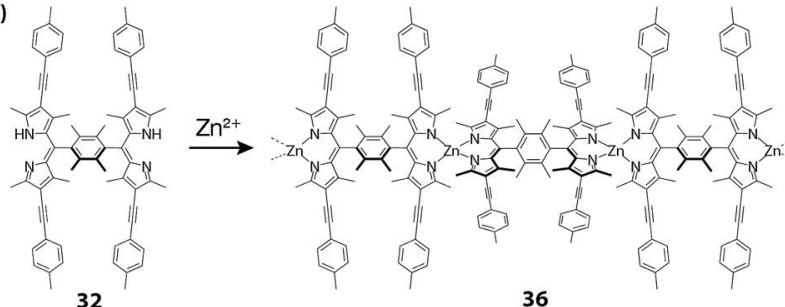

32
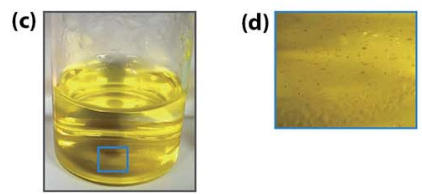

(f)

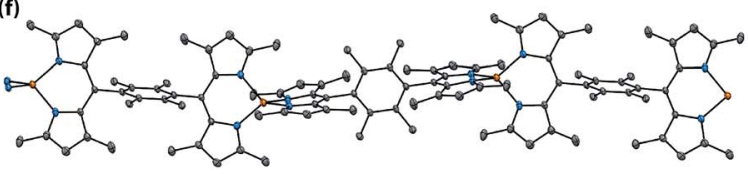

(g)
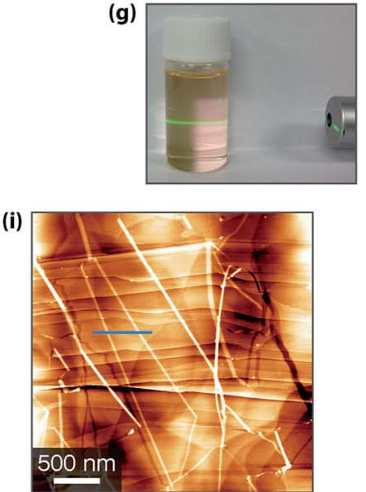

(k)

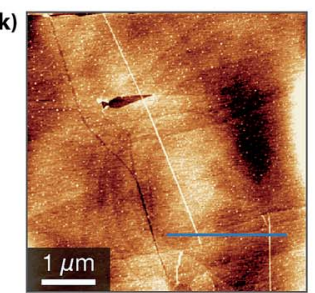

(h)
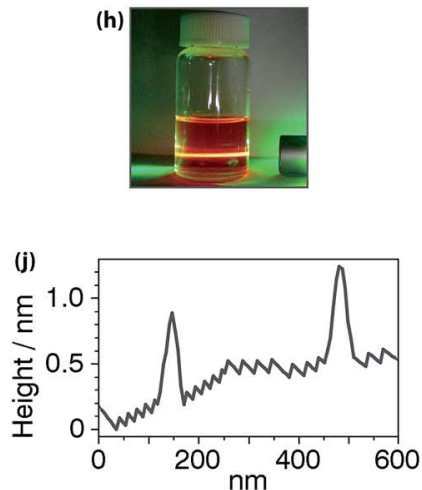

(I)

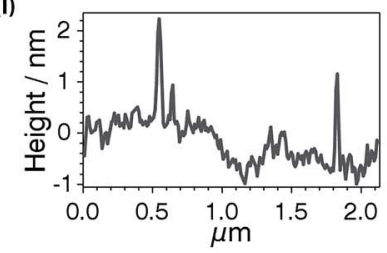

Fig. 14 (a and b) Bridging dipyrrin ligands 31 and 32, and corresponding bis(dipyrrinato)metal(I) complexes 33-36. (c) Photograph of the interfacial reaction system after the emergence of single crystals of 33. (d) Close-up image at the liquid/liquid interface shown as a blue square in (c). (e) Representative single crystal of 33. (f) ORTEP drawing of 33 with a thermal ellipsoid set at the $50 \%$ probability level (C, gray; N, blue; Zn, orange). (g) Tyndall scattering from a dichloromethane colloidal suspension of 33. (h) Dichloromethane dispersion of 36 irradiated with a green laser. Tyndall scattering was concealed by orange fluorescence from 36. (i and j) AFM height image and cross-section analysis along the blue line for 33. ( $\mathrm{k}$ and $\mathrm{l})$ AFM height image and cross-section analysis along the blue line for 36 . Adapted with permission from ref. 75 . Copyright 2015 The Royal Chemical Society.

series of AFM images of single-layer 37 transferred onto a hydrophobized silicon(111) substrate. The domain size exceeds $10 \mu \mathrm{m}$ on one side, which is very large for molecule-based nanosheet materials. An interesting investigation was conducted using the AFM tip-scratch method (Fig. 15l-n). Upon making a scratch, only "soft" nanosheet $\mathbf{3 7}$ was removed, leaving the substrate surface intact. A cross-section analysis traversing one of the scratched edges revealed a step size of 1.2 $\mathrm{nm}$, which is consistent with the size of the bis(dipyrrinato)zinc(II) complex motif. Therefore, the AFM tip-scratch experiment proved the single-layer nature of nanosheet 37 .

\subsection{Metal-organic frameworks and porous coordination polymers}

A number of coordination polymers have been developed and investigated within the context MOFs and PCPs. These polymers are expected to be promising and versatile functional materials because of their diverse structures and tunability derived from their organic ligands and metals. Tens of MOFs have been constructed using dipyrrin ligands and metal ions toward the realization of photofunctional MOFs.

Baudron and Hosseini developed a series of crystalline coordination polymers. ${ }^{80-87}$ They utilized heterometallic bis(dipyrrinato)metal complex networks using dipyrrin ligands with pyridine or benzonitrile at the meso-position. These peripheral $\mathrm{N}$-bearing moieties may be utilized as additional coordination sites for silver(I) $)^{80-82}$ and cadmium(III) ${ }^{83,84}$ centers to form heterometallic coordination polymers. Moreover, silver(I) ions may experience silver(I) $-\pi$ interactions, which also contribute to network formation. Because the metal centers of bis(dipyrrinato)copper(II), nickel(II), and cadmium(II) complexes still have room for extra coordination, they can accept the peripheral pyridine to form polymeric structures.$^{80,82,85-87}$ A good example is a series of luminescent MOFs comprising bis(dipyrrinato)cadmium(II) complexes (39 in Fig. 16). ${ }^{86}$

They also revealed that heterometallic MOFs with defined structures can be obtained by a similar one-pot method. They reacted a 4-pyridine or 4-(1H-imidazol-1-yl)benzene-appended dipyrrin ligand (40a,b), a cadmium(II) salt, and either of a zinc(II), copper(II), or palladium(II) salt to afford heterometallic MOFs (Fig. 17). In the MOFs, the pyridine moieties were bound to cadmium(II) centers, whereas the dipyrrin moieties bound to zinc(II), copper(II), or palladium(II) centers, reflecting the difference of the affinity of the metals and the coordination sites. The MOFs synthesized by the one-pot method were identical to those prepared by a sequential method, which involves the synthesis of a bis(dipyrrinato)metal complex, followed by a reaction with a cadmium(II) salt (Fig. 17). ${ }^{84}$

Cohen also developed several series of MOFs, ${ }^{88-94}$ in which nitrogen-bearing heterocycles, ${ }^{88-90,94}$ nitriles, ${ }^{91}$ carboxylates $^{92,93}$ or thiols ${ }^{76}$ were introduced at the meso-position of dipyrrin ligands. One series involved three-fold symmetric tris(dipyrrinato)iron(III) and cobalt(III) complexes with heterocycles, namely, pyridyl, quinolyl, (4-pyridylethynyl)phenyl groups (e.g. 


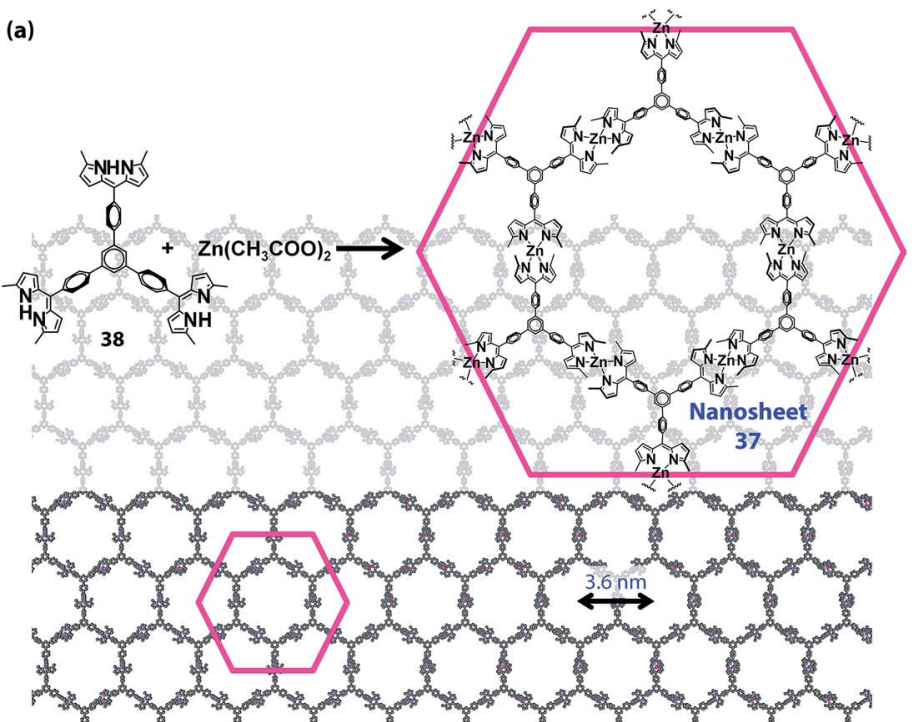

(b)
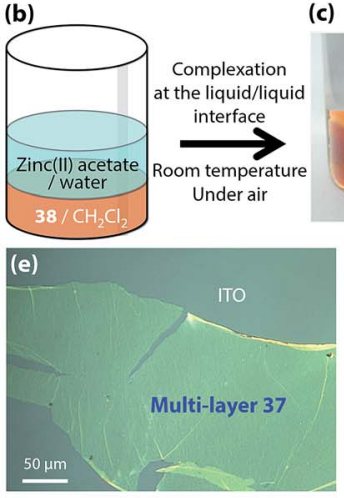

(c)

(d)

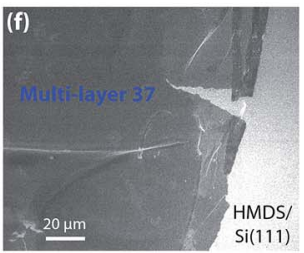

(h)
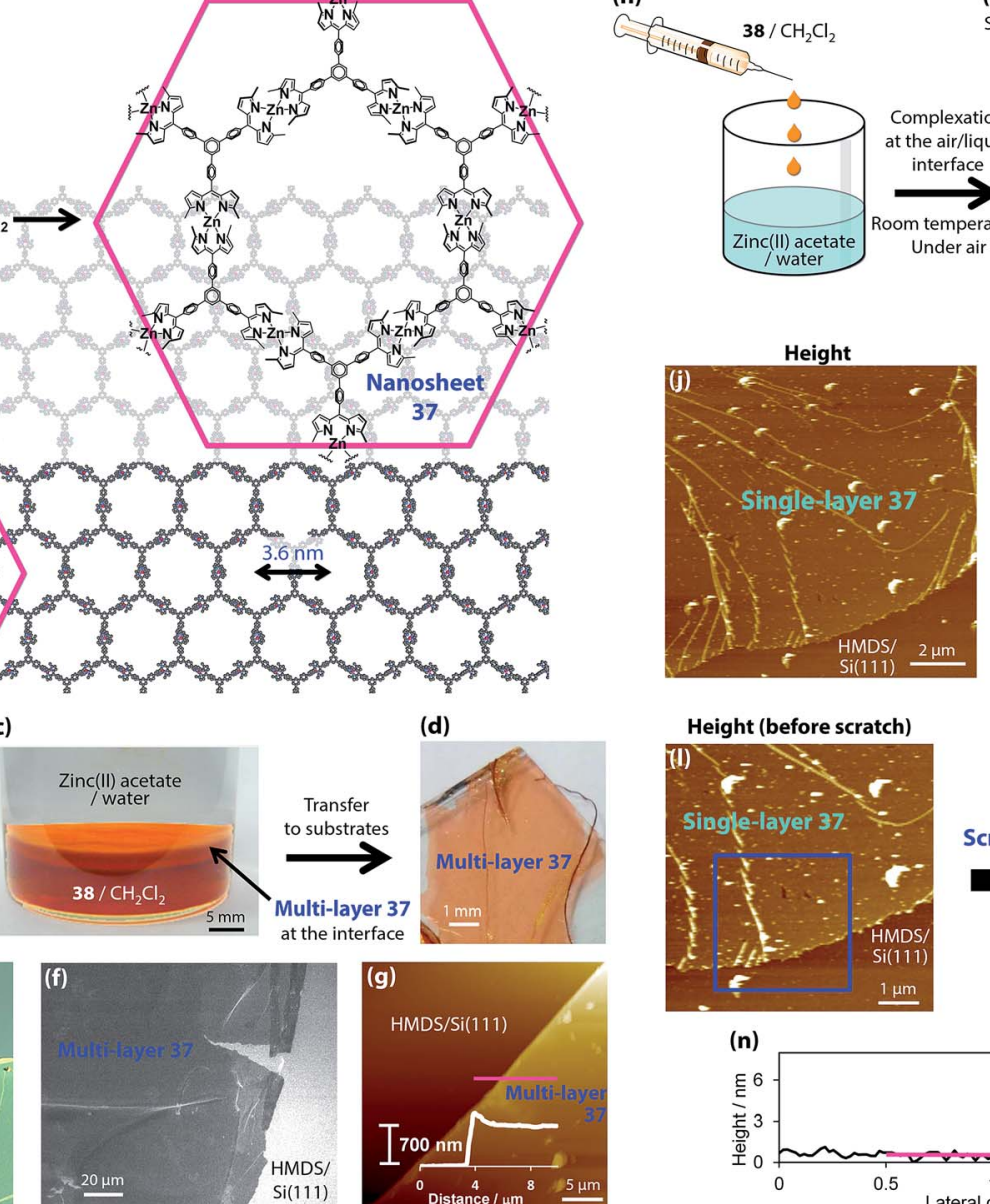

(i)

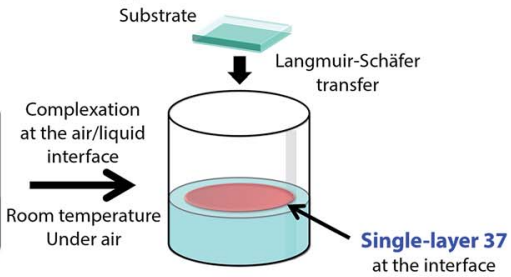
at the interface
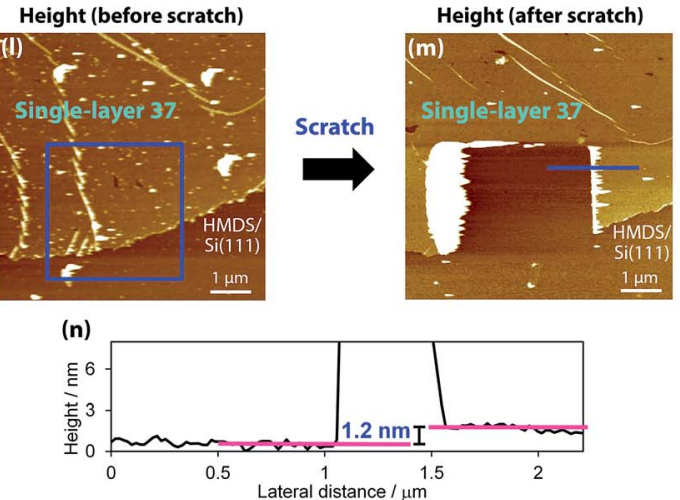

Fig. 15 Chemical structures of three-way dipyrrin ligand molecule 38 and bis(dipyrrinato)zinc(II) complex nanosheet 37 . (b) Schematic illustration of the liquid/liquid interfacial synthesis. (c) Photograph of the liquid/liquid interfacial synthesis holding multi-layer 37 at the interface. (d) Multi-layer 37 transferred onto an ITO substrate. (e) Optical microscopic image of an ITO substrate. (f) Field-emission scanning electron microscopic (FE-SEM) image of a 1,1,1,3,3,3-hexamethyldisilazane-modified silicon(111) [HMDS/Si(111)] substrate. (g) Atomic force microscopic image of HMDS/Si(111) and its cross-section analysis along the magenta line. (h) Schematic illustration of the air/liquid interfacial synthesis. (i) Schematic illustration of single-layer 37 at the air/liquid interface. ( $\mathrm{j}$ and $\mathrm{k}$ ) Height and phase images. ( $\mathrm{l}$ and $\mathrm{m}$ ) Height images before and after a scratch by the AFM tip. The blue square indicates the scratched region. (n) Cross-section analysis at one of the steps in the scratched region (shown as a blue line in m). Adapted with permission from ref. 79. Copyright 2015 Macmillan Publishers Limited.

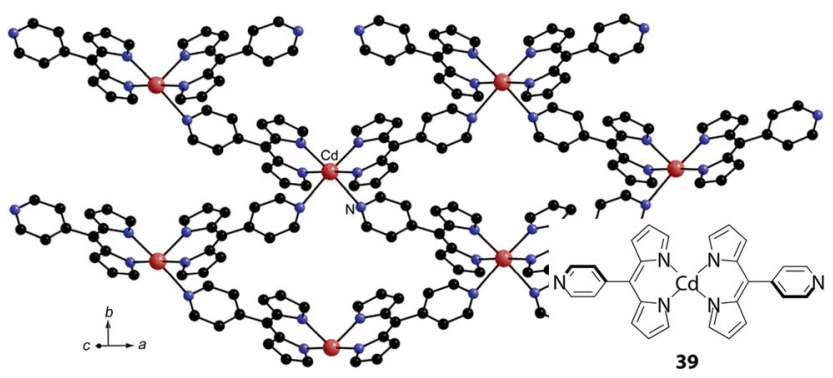

Fig. 16 Luminescent coordination polymer based on pyridineappended bis(dipyrrinato)cadmium(॥) complex 39. Adapted with permission from ref. 86. Copyright 2013 Wiley-VCH Verlag GmbH \& Co. KGaA, Weinheim Chem.

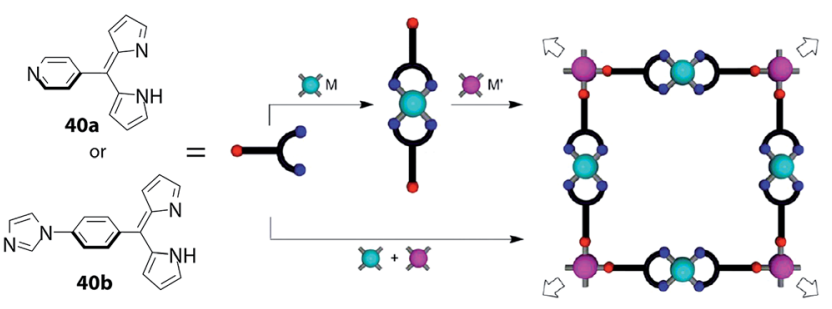

Fig. $172 \mathrm{D}$ grid heterometallic metal-organic frameworks based on heterocycle-bearing dipyrrins (40a and 40b). $M=C d(॥), M^{\prime}=\mathrm{Zn}(॥)$, $\mathrm{Cu}(॥)$, or $\mathrm{Pd}(॥)$. Adapted with permission from ref. 84. Copyright 2013 American Chemical Society.

41 in Fig. 18). ${ }^{88}$ They referred to these ligands as "metalloligands." A systematic investigation of their assemblies induced by silver(I) ions was conducted, along with a structural analysis of the resultant MOFs (Fig. 18). The counter anion for 


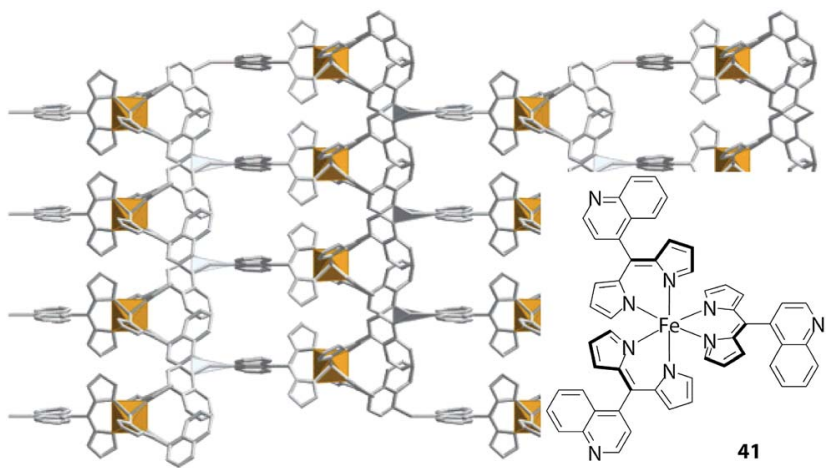

Fig. 18 Metal-organic framework comprising tris(dipyrrinato)iron(III) complex 41 with 4-quinolyl groups at the meso-position. Adapted with permission from ref. 88. Copyright 2006 American Chemical Society.

the silver(I) ions was observed to affect the structure and topology of the MOFs. The MOFs also underwent peculiar anion exchange reactions, preserving their structures.

\section{Materials applications}

In the previous section, a series of elaborate supramolecular and coordination polymeric architectures was introduced, most of which exploit spontaneous and facile coordination reactions between dipyrrin ligands and metal ions. However, the bis(dipyrrinato)metal(II) complex motif, especially that with a zinc(II) center, absorbs and emits light intensely. Therefore, the motif may also be utilized as a light-harvesting, exciton-transmitting, and emitting subunit. Thus, by integrating bis(dipyrrinato)zinc(II) complexes into supramolecular assemblies and polymer systems, the resultant architectures are expected to induce certain photofunctionalities. In the following section, a few examples of such architectures are described.

\subsection{Electron and energy transfer systems}

Guldi and co-workers demonstrated that a bis(dipyrrinato)zinc(II) complex serves as a light-absorbing and electron-donating unit upon combination with fullerene, an electron acceptor (Fig. 19). ${ }^{95}$ They designed triad 42 with two fullerene units linked by a bis(dipyrrinato)zinc(II) complex. The triad may be synthesized in a self-assembled fashion from a fullereneappended dipyrrin ligand and zinc(II) ions. A spectroscopic study of the triad demonstrated that upon photoexcitation at the bis(dipyrrinato)zinc(II) unit with $480 \mathrm{~nm}$ light, a rapid charge-separation process follows, in which the photoexcited bis(dipyrrinato)zinc(II) unit serves as an electron donor. The lifetime of the charge-separated state is approximately $1 \mathrm{~ns}$, with slight variations between different solvents.

Another example of utilizing the bis(dipyrrinato)zinc(II) complex motif as a light absorbent was demonstrated by Lindsey and co-workers (Fig. 20). ${ }^{96}$ They developed several triads with a general formula of porphyrin-bis(dipyrrinato)zinc(II) complex-porphyrin, such as 43 (Fig. 20). The UV/vis/NIR absorption spectrum of $\mathbf{4 3}$ was a simple superposition of the

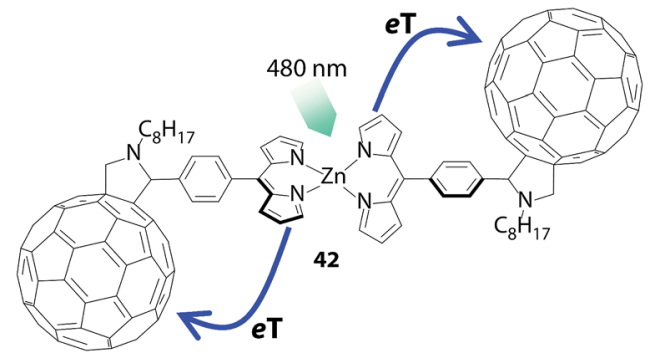

Fig. 19 Hybrid supramolecule 42 comprising fullerene and bis(dipyrrinato)zinc(II) complex units. eT denotes electron transfer.

spectra of the complex's components. In contrast, the bis(dipyrrinato)zinc(II) unit showed no contribution to the fluorescence spectrum of 43; instead, only the zinc(II) porphyrin unit emitted luminescence. The authors interpreted this series of phenomena as quantitative energy transfer from the bis(dipyrrinato)zinc(II) complex to porphyrin units.

Sakamoto and Nishihara developed asymmetric linear assemblies of bis(dipyrrinato)zinc(II) complexes bearing anthracene, plain and $\pi$-extended dipyrrin ligands (44, Fig. 21a). ${ }^{97}$ The three types of pigment moieties align in the order of photoexcitation energies from left to right, thereby an exciton ought to be transferred from the anthracene to the $\pi$ extended dipyrrin moiety through the plain dipyrrin linkers. In fact, the UV/vis/NIR absorption spectra of these dinuclear complexes are simple superpositions of the spectra of the pigment units, whereas their fluorescence spectra show features attributed to the $\pi$-extended dipyrrin at high efficiencies (up to a $\phi_{\mathrm{F}}$ of 0.78 ), with the complete absence of emission from the rest (Fig. 21b). Moreover, the selective photoexcitation of each pigment converged to the identical $\phi_{\mathrm{F}}$ and fluorescence lifetime. This series of investigations proved the presence of fast, quantitative, unidirectional energy transfer from the anthracene and plain dipyrrin to the $\pi$-extended dipyrrin unit. In conjunction with the ability to collect a broad range of UV and visible light, the series of photochemical properties allows asymmetric dinuclear complexes $\mathbf{4 4}$ to be fashioned into artificial light-harvesting systems and molecular photonic wires. 98-105 $^{\text {18 }}$

\subsection{Thermoelectric conversion}

As described in Section 3.2, one-dimensional coordination polymers 33 and 36 are dispersible in organic solvents,

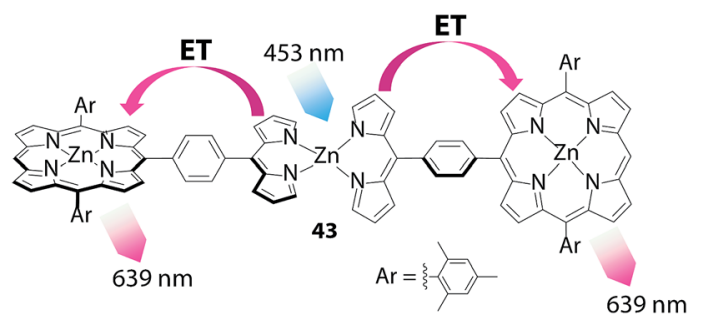

Fig. 20 Conjugate 43 between zinc(॥) porphyrin and an intervening bis(dipyrrinato)zinc(॥) complex. ET denotes energy (exciton) transfer. 
(a) $365 \mathrm{~nm}$

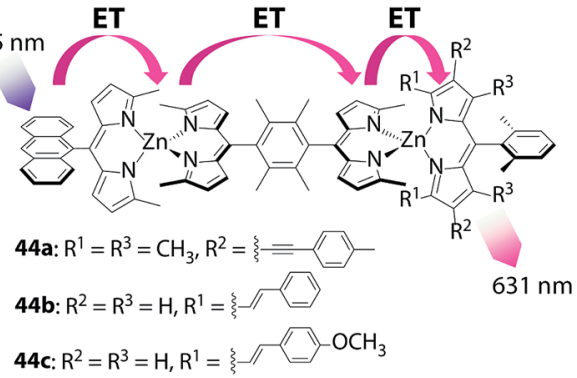

(b)

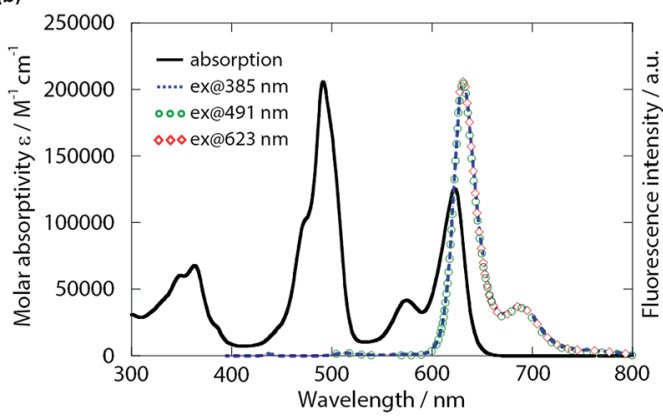

Fig. 21 (a) Asymmetric linear bis(dipyrrinato)zinc(॥) complexes 44. (b) UV/vis/NIR and luminescence spectra of $44 \mathrm{c}$ in toluene. ET denotes energy (exciton) transfer. Adapted with permission from ref. 97. Copyright 2014 The Royal Chemical Society.

retaining their chain structure. Taking advantage of their processability, Sakamoto and Nishihara attempted to form a conjugate between $\mathbf{3 3}$ and single-wall carbon nanotubes (SWCNTs). ${ }^{75}$ Nonoguchi and Kawai previously demonstrated that SWCNTs physisorbed with small organic molecules may control their carrier type and may enhance their thermoelectric conversion ability. ${ }^{106}$ A dispersion of 33 and SWCNTs $(1: 10$ $\mathrm{w} / \mathrm{w}$ ) in DMF was ultrasonicated and shaken and then filtered off to afford a free-standing film of the conjugate 33-SWCNT (Fig. 22a). Transmission electron microscopy accompanied by electron energy-loss spectroscopy (TEM/EELS) demonstrated the existence of zinc, which was distributed uniformly on the $\mathbf{3 3}$ carbon scaffold derived from SWCNTs (Fig. 22b-e). Thus, 33 coiled around the SWCNTs uniformly. The thermoelectric conversion ability of 33-SWCNT was evaluated based on a power factor of $\alpha^{2} \sigma$, where $\alpha$ and $\sigma$ denote the Seebeck coefficient and electrical conductivity, respectively. 33-SWCNT showed $\alpha$ and $\sigma$ values of $+66.2 \mu \mathrm{V} \mathrm{K} \mathrm{K}^{-1}$ (Fig. 22f) and $76.5 \mathrm{~S} \mathrm{~cm}^{-1}$, thereby demonstrating a power factor of $33 \mu \mathrm{W} \mathrm{m}{ }^{-1} \mathrm{~K}^{-2}$. These values all exceed those of pristine SWCNTs $\left(\alpha=+56.1 \mu \mathrm{V} \mathrm{K}{ }^{-1}, \sigma=29.5\right.$ $\mathrm{S} \mathrm{cm}{ }^{-1}$, and $\left.\alpha^{2} \sigma=9.3 \mu \mathrm{W} \mathrm{m}{ }^{-1} \mathrm{~K}^{-2}\right) .{ }^{106}$ The enhancement in the thermoelectric conversion ability of SWCNTs by 33 is also superior to that observed for small organic molecules $\left(\alpha^{2} \sigma<26\right.$ $\left.\mu \mathrm{W} \mathrm{m}^{-1} \mathrm{~K}^{-2}\right) .{ }^{106}$

\subsection{Photoelectric conversion}

Two-dimensional polymer 37 described in Section 3.3 belongs to the "bottom-up" type of nanosheets, which are woven directly from atomic, ionic, and molecular components. ${ }^{107}$ Research in this field has emerged; for example, single-layer cycloaddition- (a)
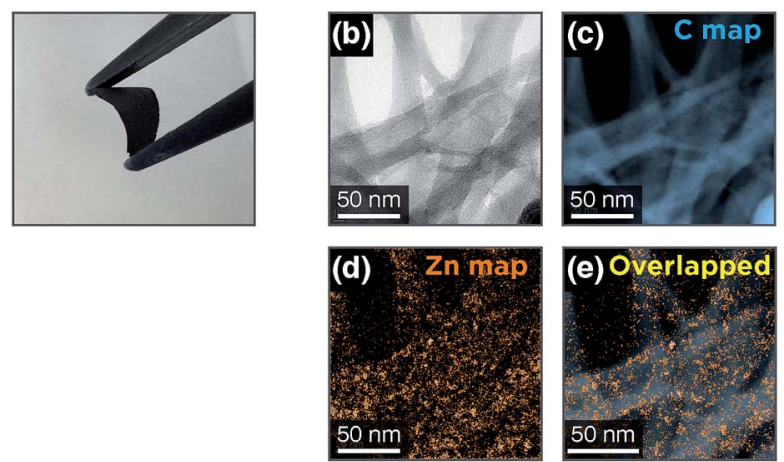

(f)

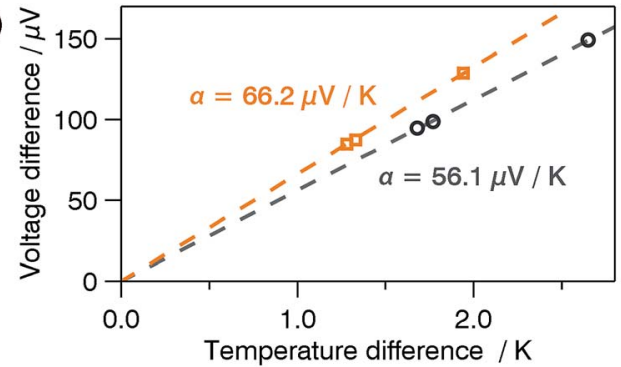

Fig. 22 (a) Photograph of a free-standing film of 33-SWCNT with a thickness of $64 \mu \mathrm{m}$. (b) Bright-field-TEM image of 33-SWCNT subjected to electron energy-loss spectroscopy (EELS) mapping. EELS mapping for: (c) carbon $\mathrm{K}$ edge intensity and (d) zinc $\mathrm{M} 2$ and $\mathrm{M} 3$ edge intensities. (e) Overlapped image of (b) and (c). (f) Voltage-difference/ temperature difference plots for pristine SWCNTs (black) and 33SWCNT (orange). Adapted with permission from ref. 75. Copyright 2015 The Royal Chemical Society.

induced anthracene nanosheets featuring carbon-carbon covalent bonds, ${ }^{108-111}$ bis(2,2': $6^{\prime}, 2^{\prime \prime}$-terpyridine)metal complex nanosheets, ${ }^{112,113}$ and a carbon-rich nanosheet synthesized from carbonization of an amphiphilic hexane molecule ${ }^{\mathbf{1 1 4}}$ have been reported within the past five years. A distinctive characteristic of bottom-up nanosheets is that structures can be customized through the design and selection of components. This feature represents an advantage over the "top-down" type of nanosheets, such as graphene and metal dichalcogenides, the structure of which is confined by the bulk layered material from which the sheets are derived. This series of reports on the synthesis of bottom-up nanosheets, however, has concentrated on the fabrication and analysis of various two-dimensional structures, and no functionality has yet been demonstrated..$^{115-119}$

In this context, Sakamoto and Nishihara pursued the application of bottom-up nanosheet 37 in a photoelectric conversion system, taking advantage of the intense ${ }^{1} \pi-\pi^{*}$ absorption of the material. ${ }^{79}$ We note that several mono(dipyrrinato)ruthenium(II) ${ }^{\mathbf{1 2 0 - 1 2 2}}$ and copper(I) ${ }^{\mathbf{1 2 3}}$ complexes were employed as pigments in dye-sensitized solar cells (DSSCs). A transparent $\mathrm{SnO}_{2}$ electrode was decorated with 36-layer 37, which was used as a working electrode (photoanode). The modified $\mathrm{SnO}_{2}$ electrode was incorporated into a three-electrode system, and a photoelectric conversion cell thereof was established using an acetonitrile electrolyte solution. Triethanolamine (TEOA) was also added as a sacrificial electron donor. An anodic current was gained only when the working electrode was irradiated with 
$500 \mathrm{~nm}$ light, corresponding to the absorption maximum of 37 (Fig. 23a). The action spectrum shown in Fig. 23b shows that the maximal photocurrent was acquired with $500 \mathrm{~nm}$ light, whereas no response was observed when using light outside of the range of the ${ }^{1} \pi-\pi^{*}$ absorption. Control experiments that lacked either 37 or TEOA did not show a photocurrent response at all. These findings indicate that the observed photocurrent stemmed from the photocatalytic oxidation of TEOA, which was initiated by the photoexcitation of 37 on the $\mathrm{SnO}_{2}$ electrode. The highest quantum yield reaches $0.86 \%$, which is far greater than that of a mononuclear bis(dipyrrinato)zinc(II) complex sensitizer physisorbed on $\mathrm{anO}_{2}$ electrode $(0.030 \%$ in an aqueous electrolyte solution) and that of a sensitizer chemisorbed on the electrode through the carboxylate-metal oxide protocol $(0.069 \%)$. The nanosheet structure of 37 affords suitable porosity and suppresses molecular aggregation, which presumably makes 37 a better sensitizer. In addition, single-layer 37 may be accumulated stepwise on a flat substrate to form a film with a desired thickness. For example, 37 synthesized by the air/liquid interfacial process (Fig. 15h and i) on a Langmuir-Blodgett trough was deposited iteratively on a quartz substrate at a constant surface pressure using the Langmuir-Schäfer method. The peak absorbance of the ${ }^{1} \pi-\pi^{*}$ band at $500 \mathrm{~nm}$ was proportional to the number of deposition processes (Fig. 23c and d), which indicated the quantitative, layer-by-layer accumulation of single-layer 37 . Thus, 37 is the first photofunctional bottom-up nanosheet that exhibits both insolubility (to avoid redissolution into media) and tunability (to facilitate deposition and layering), making it useful for various potential applications.
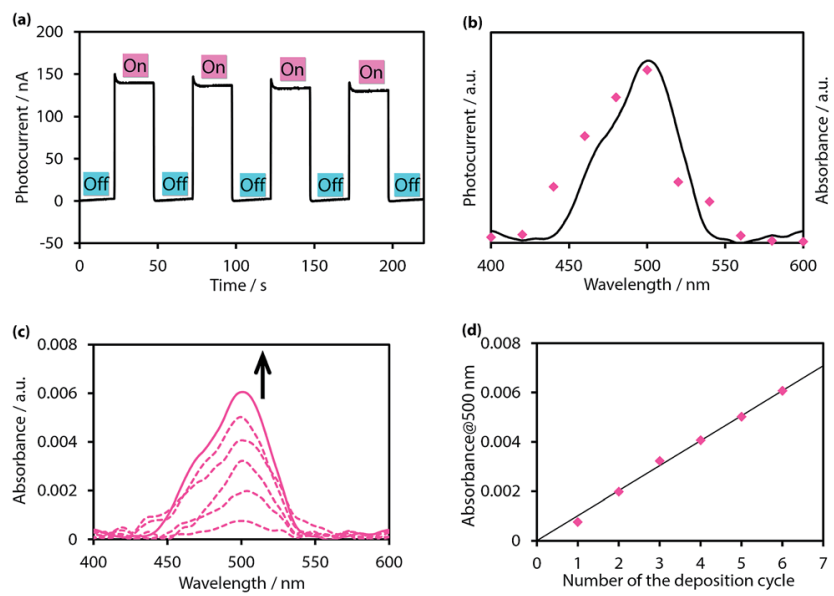

Fig. 23 (a) Typical anodic current response upon irradiation of a working electrode $\left(\mathrm{SnO}_{2}\right.$ substrate modified with 36-layer 37$)$ with intermittent $500 \mathrm{~nm}$ light in an acetonitrile electrolyte solution (0.1 M tetrabutylammonium perchlorate with $0.05 \mathrm{M}$ TEOA) (b) action spectrum for the photocurrent generation (magenta dots) and absorption spectrum of 37 (black solid line). (c) Absorption spectral change upon stepwise depositions of single-layer 37 on a quartz substrate. (d) Linear relationship between the absorbance at $500 \mathrm{~nm}$ and the number of deposition processes. The magenta dots are extracted from Fig. 23c, and the black solid line corresponds to the least-squares linear fit of the plots. Adapted with permission from ref. 79. Copyright 2015 Macmillan Publishers Limited.
Sakamoto and Nishihara also reported that one-dimensional bis(dipyrrinato)zinc(II) coordination polymers 33 and 36 could be applied in photoelectric conversion (Fig. 24). ${ }^{75}$ The processability of $\mathbf{3 3}$ and $\mathbf{3 6}$ or their dispersibility in organic solvents allowed the authors to fabricate thin films on $\mathrm{SnO}_{2}$ electrodes by dropcasting their dispersions (Fig. 24a and d). A photoelectric conversion system was prepared in a manner similar to that used to produce nanosheet 37, using a $\mathrm{SnO}_{2}$ electrode modified as a photoanode. Again, photocurrent generation was confirmed upon excitation of 33 and 36 (Fig. 24b and e). The photoelectric conversion efficiencies were determined to be $1.0 \%$ and $0.027 \%$ for 33 (in an acetonitrile medium) and 36 (in an aqueous medium), respectively. These values are much greater than that of a mononuclear bis(dipyrrinato)zinc(II) complex sensitizer chemisorbed on the electrode $0.069 \%$ and $0 \%$ in, respectively, acetonitrile and aqueous media). It is also noteworthy that the responsive wavelength range of the photoelectric conversion may be tuned: the maximal photocurrent was observed to occur with $500 \mathrm{~nm}$ light in 33, whereas that of 36 underwent a bathochromic shift by $40 \mathrm{~nm}$ (Fig. 23c and $\mathrm{f}$ ). Such a redshift is esteemed in photoelectric conversion applications and can certainly be attained due to the designability and tunability of the present one-dimensional polymer system. (a)
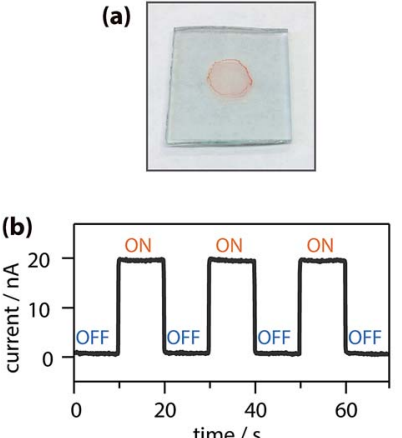

(c)

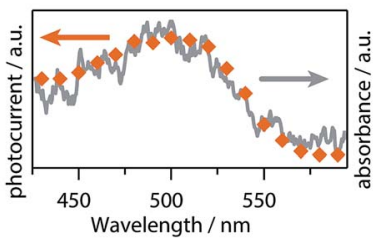

(d)
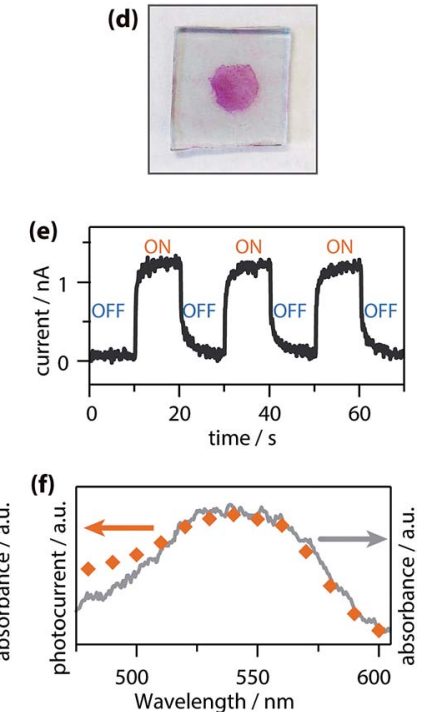

Fig. 24 (a) Photograph of a thin film of 33 on a $\mathrm{SnO}_{2}$ electrode. (b) Typical anodic photocurrent response upon irradiation of a working electrode $\left(\mathrm{SnO}_{2}\right.$ substrate modified with 33 as shown in (a)) with intermittent $500 \mathrm{~nm}$ light in an acetonitrile electrolyte solution (0.1 M tetrabutylammonium perchlorate with $0.05 \mathrm{M}$ TEOA). (c) Action spectrum for the photocurrent generation (orange dots) and absorption spectrum of 33 on a $\mathrm{SnO}_{2}$ substrate (gray solid line). (d) Photograph of a thin film of 36 on a $\mathrm{SnO}_{2}$ electrode. (e) Typical anodic photocurrent response upon irradiation of a working electrode $\left(\mathrm{SnO}_{2}\right.$ substrate modified with 36 as shown in (d)) with intermittent $550 \mathrm{~nm}$ light in an aqueous electrolyte solution (0.1 M sodium sulfate with 0.03 $M$ TEOA). (f) Action spectrum for the photocurrent generation (orange dots) and absorption spectrum of 36 on a $\mathrm{SnO}_{2}$ substrate (gray solid line). Adapted with permission from ref. 75. Copyright 2015 The Royal Chemical Society. 


\section{Conclusions}

To date, a tremendous number of reports related to dipyrrins have been published, although most of them focus on BODIPYs, $\mathrm{BF}_{2}$ complexes of dipyrrins, rather than other dipyrrin metal complexes. Researchers have been attracted to the enticing nature of BODIPYs as fluorescent chromophores, in contrast to dipyrrin metal complexes, which have long been regarded as less intriguing materials due to their negligible or low luminescence efficiencies. Herein, we described the rich chemistry of bis and tris(dipyrrinato)metal complexes developed over the past fifteen years. In Section 2, careful and elaborate molecular designs for achieving bright luminescence, including the introduction of meso-aryl groups with steric hindrance and the creation of heteroleptic complexes with suitable frontier orbital ordering, were discussed. Section 3 provided an overview of supramolecules, coordination polymers, and MOFs based on the bis and tris(dipyrrinato)metal complex motifs. One of the distinctive advantages of dipyrrin metal complexes over BODIPYs is the spontaneous formation of the coordination bonds, which allows for the formation of a series of self-assembled supramolecular and polymeric architectures in conjunction with the appropriate design of dipyrrin ligands, such as oligo(dipyrrin)s and those with additional coordination sites. The favorable features and characteristic structures demonstrated to date potentially renders bis and tris(dipyrrinato)metal complexes valuable materials. Reported attempts to produce such materials have been presented in Section 4, which discussed how methods based on photoinduced charge separation, fast, quantitative, unidirectional exciton transport, and thermoelectric and photoelectric conversion have been pursued. The remarkable progress made in bis and tris(dipyrrinato)metal complex chemistry represents a milestone toward the development of profound science and real-world applications.

\section{Acknowledgements}

The present paper is chiefly supported by Grants-in-Aid from the MEXT of Japan (no. 25107510 and area 2406 [All Nippon Artificial Photosynthesis Project for Living Earth]). The authors also acknowledge Grants-in-Aid from the MEXT of Japan (nos 24750054, 26708005, 26107510, 26620039, area 2506 [Science of Atomic Layers]). R.S. is grateful to Ogasawara Foundation for the Promotion of Science \& Engineering, Noguchi Institute, Tokuyama Science Foundation, Asahi Glass Foundation, The Murata Science Foundation, Iketani Science and Technology Foundation, The Japan Prize Foundation, Kao Foundation for Arts and Sciences, Japan Association for Chemical Innovation, The MIKIYA Science and Technology Foundation, Yazaki Memorial Foundation for Science and Technology, Shorai Foundation for Science and Technology, The Kurata Memorial Hitachi Science and Technology Foundation, and Kumagai Foundation for Science and Technology for financial support. M.T. and R.M. acknowledge JSPS fellowship for young scientists. M.T. is also grateful to Advanced Leading Graduate Course for Photon Science (ALPS). K.H. acknowledges the Fostering program of human resources in chemistry conducted by Japan Chemical Industry Association.

\section{Notes and references}

1 T. E. Wood and A. Thompson, Chem. Rev., 2007, 107, 1831.

2 S. A. Baudron, Dalton Trans., 2013, 42, 7498.

3 Y. Ding, Y. Tang, W. Zhua and Y. Xie, Chem. Soc. Rev., 2015, 44, 1101.

4 E. V. Antina, R. T. Kuznetsova, L. A. Antina, G. B. Guseva, N. A. Dudina, A. I. V'yugin and A. V. Solomonov, Dyes Pigm., 2015, 113, 664.

5 H. Lu, J. Mack, Y. Yanga and Z. Shen, Chem. Soc. Rev., 2014, 43, 4778.

6 Y. Nia and J. Wu, Org. Biomol. Chem., 2014, 12, 3774.

7 S. P. Singh and T. Gayathri, Eur. J. Org. Chem., 2014, 4689.

8 A. Kamkaew, S. H. Lim, H. B. Lee, L. V. Kiew, L. Y. Chung and K. Burgess, Chem. Soc. Rev., 2013, 42, 77.

9 S. G. Awuah and Y. You, RSC Adv., 2012, 2, 11169.

10 M. Benstead, G. H. Mehl and R. W. Boyle, Tetrahedron, 2011, 67, 3573.

11 N. Boens, V. Leen and W. Dehaen, Chem. Soc. Rev., 2012, 41, 1130.

12 H. N. Kim, W. X. Ren, J. S. Kim and J. Yoon, Chem. Soc. Rev., 2012, 41, 3210.

13 A. Loudet and K. Burgess, Chem. Rev., 2007, 107, 4891.

14 R. Ziessel, G. Ulrich and A. Harriman, New J. Chem., 2007, 31, 496.

15 A. C. Benniston and G. Copley, Phys. Chem. Chem. Phys., 2009, 11, 4124.

16 A. Bessette and G. S. Hanan, Chem. Soc. Rev., 2014, 43, 3342.

17 H. Fischer and M. Schubert, Ber. Dtsch. Chem. Ges., 1924, $57,610$.

18 I. V. Sazanovich, C. Kirmaier, E. Hindin, L. Yu, D. F. Bocian, J. S. Lindsey and D. Holten, J. Am. Chem. Soc., 2004, 126, 2664.

19 S. Lee, C.-H. Seok, Y. Park, A. Lee, D. H. Jung, S.-H. Choi and J. Park, Mol. Cryst. Liq. Cryst., 2010, 531, 65.

20 S. Kusaka, R. Sakamoto, Y. Kitagawa, M. Okumura and H. Nishihara, Chem.-Asian J., 2012, 7, 907.

21 R. Toyoda, M. Tsuchiya, R. Sakamoto, R. Matsuoka, K.-H. Wu, Y. Hattori and H. Nishihara, Dalton Trans., 2015, DOI: 10.1039/c5dt00724k.

22 M. Zander and W. Rettig, Chem. Phys. Lett., 1984, 110, 602. 23 T. J. Kang, M. A. Kahlow, D. Giser, S. Swallen, V. Nargarajan, W. Jarzeba and P. F. Barbara, J. Phys. Chem., 1988, 92, 6800.

24 E. Vauthey, ChemPhyschem, 2012, 13, 2001.

25 S. R. Halper, J. R. Stork and S. M. Cohen, Dalton Trans., 2007, 1067.

26 I. Szymańska, M. Stobiecka, C. Orlewska, T. Rohand, D. Janssen, W. Dehaen and H. Radecka, Langmuir, 2008, 24, 11239.

27 I. Grabowska, W. Maes, T. H. Ngo, T. Rohand, W. Dehaen, J. Radecki and H. Radecka, Int. J. Electrochem. Sci., 2014, 9, 1232.

28 Q. Miao, J.-Y. Shin, B. O. Patrick and D. Dolphin, Chem. Commun., 2009, 2541. 
29 C. Trinh, K. Kirlikovali, S. Das, M. E. Ener, H. B. Gray, P. Djurovich, S. E. Bradforth and M. E. Thompson, J. Phys. Chem. C, 2014, 118, 21834.

30 V. S. Thoi, J. R. Stork, D. Magde and S. M. Cohen, Inorg. Chem., 2006, 45, 10688.

31 S. Kusaka, R. Sakamoto and H. Nishihara, Inorg. Chem., 2014, 53, 3275.

32 T. S. Teets, D. V. Partyka, J. B. Updegraff III and T. G. Gray, Inorg. Chem., 2008, 47, 2338.

33 A. Palma, J. F. Gallagher, H. Müller-Bunz, J. Wolowska, E. J. L. McInnes and D. F. O'shea, Dalton Trans., 2009, 273.

34 M. R. Gresser, A. Hoyer, M. Hummert, H. Hartmann, K. Leo and M. Riede, Dalton Trans., 2011, 40, 3476.

35 R. Sakamoto, S. Kusaka, Y. Kitagawa, M. Kishida, M. Hayashi, Y. Takara, M. Tsuchiya, J. Kakinuma, T. Takeda, K. Hirata, T. Ogino, K. Kawahara, T. Yagi, S. Ikehira, T. Nakamura, M. Isomura, M. Toyama, S. Ichikawa, M. Okumura and H. Nishihara, Dalton Trans., 2012, 41, 14035.

36 J. D. Hall, T. M. McLean, S. J. Smalley, M. R. Waterland and G. Telfer, Dalton Trans., 2010, 39, 437.

37 T. S. Teets, D. V. Partyka, A. J. Esswein, J. B. Updegraff III, M. Zeller, A. D. Hunter and T. G. Gray, Inorg. Chem. Commun., 2007, 46, 6218.

38 X. Liu, H. Nan, W. Sun, Q. Zhang, M. Zhan, L. Zou, Z. Xie, X. Li, C. Lud and Y. Cheng, Dalton Trans., 2012, 41, 10199.

39 T. E. Hewat, L. J. Yellowlees and N. Robertson, Dalton Trans., 2014, 43, 4127.

40 T. M. McLean, J. L. Moody, M. R. Waterland and S. G. Telfer, Inorg. Chem., 2012, 51, 446.

41 C. Bronner, S. A. Baudron, M. W. Hosseini, C. A. Strassert, A. Guenet and L. De Cola, Dalton Trans., 2010, 39, 180.

42 K. Hanson, A. Tamayo, V. V. Diev, M. T. Whited, P. I. Djurovich and M. E. Thompson, Inorg. Chem., 2010, 49, 6077.

43 C. Bronner, S. A. Baudron and M. W. Hosseini, Inorg. Chem., 2010, 49, 8659.

44 C. Bronner, M. Veiga, A. Guenet, M. W. Hosseini, L. De Cola, C. A. Strassert and S. A. Baudron, Chem.-Eur. J., 2012, 18, 4041.

45 D. Ramlot, M. Rebarz, L. Volker, M. Ovaere, D. Beljonne, W. Dehaen, L. Van Meervelt, C. Moucheron and A. KirschDe Mesmaeker, Eur. J. Inorg. Chem., 2013, 2031.

46 S. M. Crawford, A. Al-Sheikh Ali, T. S. Cameron and A. Thompson, Inorg. Chem., 2011, 50, 8207.

47 C. Ikeda, S. Ueda and T. Nabeshima, Chem. Commun., 2009, 2544.

48 N. Sakamoto, C. Ikeda, M. Yamamura and T. Nabeshima, J. Am. Chem. Soc., 2011, 133, 4726.

49 M. A. Filatov, A. Y. Lebedev, S. N. Mukhin, S. A. Vinogradov and A. V. Cheprakhov, J. Am. Chem. Soc., 2009, 132, 9552.

50 M. Ishida, Y. Naruta and F. Tani, Angew. Chem., Int. Ed., 2010, 49, 91.

51 M. Ishida, J. M. Lin, B. S. Lee, F. Tani, J. L. Sessler, D. Kim and Y. Naruta, Chem.-Eur. J., 2012, 18, 14329.

52 Y. Zhang, A. Thompson, S. J. Rettig and D. Dolphin, J. Am. Chem. Soc., 1998, 120, 13537.
53 A. Thompson and D. Dolphin, Org. Lett., 2000, 2, 1315.

54 A. Thompson and D. Dolphin, J. Org. Chem., 2000, 65, 7870.

55 Q. Chen, Y. Zhang and D. Dolphin, Tetrahedron Lett., 2002, 43, 8413.

56 L. Yang, Y. Zhang, G. Yang, Q. Chen and J. S. Ma, Dyes Pigm., 2004, 62, 27.

57 T. E. Wood, N. D. Dalgleish, E. D. Power, A. Thompson, X. Chen and Y. Okamoto, J. Am. Chem. Soc., 2005, 127, 5740.

58 T. Hashimoto, T. Nishimura, J. M. Lim, D. Kim and H. Maeda, Chem.-Eur. J., 2010, 16, 11653.

59 H. Maeda, T. Nishimura, R. Akuta, K. Takaishi, M. Uchiyama and A. Muranaka, Chem. Sci., 2013, 4, 1204. 60 Q. Chen and D. Dolphin, Can. J. Chem., 2002, 80, 1668.

61 A. Thompson, S. J. Rettig and D. Dolphin, Chem. Commun., 1999, 3, 631.

62 Z. Zhang and D. Dolphin, Inorg. Chem., 2010, 49, 11550.

63 L. Ma, B. O. Patrick and D. Dolphin, Chem. Commun., 2011, 47, 704.

64 H. Maeda, R. Akuta, Y. Bando, K. Takaishi, M. Uchiyama, A. Muranaka, N. Tohnai and S. Seki, Chem.-Eur. J., 2013, 19, 11676.

65 E. V. Antina, M. B. Berezin, N. A. Dudina, G. B. Guseva, L. A. Antina and A. I. V'yugin, Russ. J. Gen. Chem., 2010, 80, 1216.

66 S. A. Amelichev, A. S. Shashkov, I. V. Zavarzin and O. A. Rakitin, Mendeleev Commun., 2011, 21, 186.

67 L. A. Antina, N. A. Dudina, M. B. Berezin and G. B. Guseva, Russ. J. Gen. Chem., 2011, 81, 162.

68 L. A. Antina, N. A. Dudin, M. B. Berezin, G. B. Guseva and E. V. Antina, Russ. J. Gen. Chem., 2011, 81, 591.

69 L. A. Antina, N. A. Dudina, G. B. Guseva, M. B. Berezin and A. I. V'yugin, Russ. J. Gen. Chem., 2011, 81, 2349.

70 G. B. Guseva, L. A. Antina, E. V. Antina and A. I. Vyugin, Thermochim. Acta, 2012, 544, 54.

71 L. A. Antina, G. B. Guseva, A. I. V'yugin, E. V. Antina and M. B. Berezin, Russ. J. Gen. Chem., 2013, 83, 1143.

72 S. A. Baudron, H. Ruffin and M. W. Hosseini, Chem. Commun., 2015, 51, 5906.

73 H. Maeda, M. Hasegawa, T. Hashimoto, T. Kakimoto, S. Nishio and T. Nakanishi, J. Am. Chem. Soc., 2006, 128, 10024.

74 H. Maeda, H. Kobayashi, R. Akuta and R. J. Porphyr, Phthalocyanines, 2013, 17, 86.

75 R. Matsuoka, R. Toyoda, R. Sakamoto, M. Tsuchiya, K. Hoshiko, T. Nagayama, Y. Nonoguchi, K. Sugimoto, E. Nishibori, T. Kawai and H. Nishihara, Chem. Sci., 2015, 6, 2853.

76 L. Do, S. R. Halper and S. M. Cohen, Chem. Commun., 2004, 2662.

77 S. R. Halper, M. R. Malachowski, H. M. Delaney and S. M. Cohen, Inorg. Chem., 2004, 43, 1242.

78 S. R. Halper and S. M. Cohen, Inorg. Chem., 2005, 44, 4139. 79 R. Sakamoto, K. Hoshiko, Q. Liu, T. Yagi, T. Nagayama, S. Kusaka, M. Tsuchiya, Y. Kitagawa, W.-Y. Wong and H. Nishihara, Nat. Commun., 2015, 6, 6713.

80 A. Béziau, S. A. Baudron and M. W. Hosseini, Dalton Trans., 2012, 41, 7227. 
$81 \mathrm{H}$. Ruffin, S. A. Baudron, D. Salazar-Mendoza and M. W. Hosseini, Chem.-Eur. J., 2014, 20, 2449.

82 B. Kilduff, D. Pogozhev, S. A. Baudron and M. W. Hosseini, Inorg. Chem., 2010, 49, 11231.

83 A. Béziau, S. A. Baudron, D. Pogozhev, A. Fluck and M. W. Hosseini, Chem. Commun., 2012, 48, 10313.

84 A. Béziau, S. A. Baudron, A. Fluck and M. W. Hosseini, Inorg. Chem., 2013, 52, 14439.

85 A. Béziau, S. A. Baudron, G. Rogez and M. W. Hosseini, CrystEngComm, 2013, 15, 5980.

86 A. Béziau, S. A. Baudron, A. Guenet and M. W. Hosseini, Chem.-Eur. J., 2013, 19, 3215.

87 A. Béziau, S. A. Baudron, G. Rogez and M. W. Hosseini, Inorg. Chem., 2015, 54, 2032.

88 S. R. Halper, L. Do, J. R. Stork and S. M. Cohen, J. Am. Chem. Soc., 2006, 128, 15255.

89 S. R. Halper and S. M. Cohen, Inorg. Chem., 2005, 44, 486.

90 S. R. Halper, M. R. Malachowski, H. M. Delaney and S. M. Cohen, Inorg. Chem., 2004, 43, 1242.

91 D. L. Murphy, M. R. Malachowski, C. F. Campana and S. M. Cohen, Chem. Commun., 2005, 5506.

92 S. G. Telfer and J. D. Wuest, Cryst. Growth Des., 2009, 9, 1923.

93 S. J. Garibay, J. R. Stork, Z. Wang, S. M. Cohen and S. G. Telfer, Chem. Commun., 2007, 4881.

94 J. R. Stork, V. S. Thoi and S. M. Cohen, Inorg. Chem., 2007, 46, 11213.

95 Y. Rio, D. Sánchez-García, W. Seitz, T. Torres, J. L. Sessler and D. M. Guldi, Chem.-Eur. J., 2009, 15, 3956.

96 L. Yu, K. Muthukumaran, I. V. Sazanovich, C. Kirmaier, E. Hindin, J. R. Diers, P. D. Boyle, D. F. Bocian, D. Holten and J. S. Lindsey, Inorg. Chem., 2003, 42, 6629.

97 M. Tsuchiya, R. Sakamoto, S. Kusaka, Y. Kitagawa, M. Okumura and H. Nishihara, Chem. Commun., 2014, 50, 5881.

98 R. W. Wagner, J. S. Lindsey, J. Seth, V. Palaniappan and D. F. Bocian, J. Am. Chem. Soc., 1996, 118, 3996.

99 A. Ambroise, C. Kirmaier, R. W. Wagner, R. S. Loewe, D. F. Bocian, D. Holten and J. S. Lindsey, J. Org. Chem., 2002, 67, 3811.

100 R. W. Wagnera and J. S. Lindsey, J. Am. Chem. Soc., 1994, 116, 9759.

101 J. K. Hannestad, P. Sandin and B. Albinsson, J. Am. Chem. Soc., 2008, 130, 15889.

102 G. Sánchez-Mosteiro, E. M. H. P. van Dijk, J. Hernando, M. Heilemann, P. Tinnefeld, M. Sauer, F. Koberlin, M. Patting, M. Wahl, R. Erdmann, N. F. van Hulst and M. F. García-Parajó, J. Phys. Chem. B, 2006, 110, 26349.

103 M. Heilemann, R. Kasper, P. Tinnefeld and M. Sauer, J. Am. Chem. Soc., 2006, 128, 16864.

104 P. Tinnefeld, M. Heilemann and M. Sauer, ChemPhysChem, 2005, 6, 217.

105 M. Heilemann, P. Tinnefeld, G. S. Mosteiro, M. G. Parajo, N. F. van Hulst and M. Sauer, J. Am. Chem. Soc., 2004, 126, 6514 .
106 Y. Nonoguchi, K. Ohashi, R. Kanazawa, K. Ashiba, K. Hata, T. Nakagawa, C. Adachi, T. Tanase and T. Kawai, Sci. Rep., 2013, 3, 3344.

107 J. Sakamoto, J. van Heijst, O. Lukin and A. D. Schlüter, Angew. Chem., Int. Ed., 2009, 48, 1030.

108 P. Kissel, R. Erni, W. B. Schweizer, M. D. Rossell, B. T. King, T. Bauer, S. Götzinger, A. D. Schlüter and J. Sakamoto, Nat. Chem., 2012, 4, 287.

109 P. Payamyar, K. Kaja, C. Ruiz-Vargas, A. Stemmer, D. J. Murray, C. J. Johnson, B. T. King, F. Schiffmann, J. VandeVondele, A. Renn, S. Götzinger, P. Ceroni, A. Schütz, L.-T. Lee, Z. Zheng, J. Sakamoto and A. D. Schlüter, Adv. Mater., 2014, 26, 2052.

110 M. J. Kory, M. Wörle, T. Weber, P. Payamyar, S. W. van de Poll, J. Dshemuchadse, N. Trapp and A. D. Schlüter, Nat. Chem., 2014, 6, 779.

111 P. Kissel, D. J. Murray, W. J. Wulftange, V. J. Catalano and B. T. King, Nat. Chem., 2014, 6, 774.

112 T. Bauer, Z. Zheng, A. Renn, R. Enning, A. Stemmer, J. Sakamoto and A. D. Schlüter, Angew. Chem., Int. Ed., 2011, 50, 7879.

113 Z. Zheng, L. Opilik, F. Schiffmann, W. Liu, G. Bergamini, P. Ceroni, L.-T. Lee, A. Schütz, J. Sakamoto, R. Zenobi, J. VandeVondele and A. D. Schlüter, J. Am. Chem. Soc., 2014, 136, 6103.

114 S. Schrettl, C. Stefaniu, C. Schwieger, G. Pasche, E. Oveisi, Y. Fontana, A. Fontcuberta i Morral, J. Reguera, R. Petraglia, C. Corminboeuf, G. Brezesinski and H. Frauenrath, Nat. Chem., 2014, 6, 468.

115 Our recent reports on functional bottom-up nanosheets: T. Kambe, R. Sakamoto, T. Kusamoto, T. Pal, N. Fukui, T. Shimojima, Z. Wang, T. Hirahara, K. Ishizaka, S. Hasegawa, F. Liu and H. Nishihara, J. Am. Chem. Soc., 2014, 136, 14357.

116 T. Kambe, R. Sakamoto, K. Hoshiko, K. Takada, J.-H. Ryu, S. Sasaki, J. Kim, K. Nakazato, M. Takata and H. Nishihara, J. Am. Chem. Soc., 2013, 135, 2462.

117 K. Hoshiko, T. Kambe, R. Sakamoto, K. Takada and H. Nishihara, Chem. Lett., 2014, 43, 252.

118 K. Takada, R. Sakamoto, S.-T. Yi, S. Katagiri, T. Kambe and H. Nishihara, J. Am. Chem. Soc., 2015, 137, 4681.

119 H. Nishihara, Chem. Lett., 2014, 43, 388.

120 G. Li, P. G. Bomben, K. C. D. Robson, S. I. Gorelsky, C. P. Berlinguette and M. Shatruk, Chem. Commun., 2012, 48, 8790.

121 G. Li, K. Hu, C. Yi, K. L. Knappenberger, G. J. Meyer, S. I. Gorelsky and M. Shatruk, J. Phys. Chem. C, 2013, 117, 17399.

122 G. Li, K. Hu, K. C. D. Robson, S. I. Gorelsky, G. J. Meyer, C. P. Berlinguette and M. Shatruk, Chem.-Eur. J., 2015, 21, 2173.

123 T. E. Hewat, L. J. Yellowlees and N. Robertson, Dalton Trans., 2014, 43, 4127. 